\title{
Interaction between Markedness and Transfer in English Coda Nasals: Taiwanese Learning English as a Foreign Language
}

\author{
Hsiu-ling Hsu \\ Department of Applied English, Kun Shan University, Taiwan \\ Correspondence: Hsiu-ling Hsu, Department of Applied English, Kun Shan University, No. 949, Dawan Rd., \\ Yongkang Dist., Tainan City 71003, Taiwan (R.O.C.). E-mail: bbshally@yahoo.com.tw
}

Received: January 21, 2013 Accepted: February 6, 2013 Available online: March 11, 2013

doi:10.11114/smc.v1i1.95 URL: http://dx.doi.org/10.11114/smc.v1i1.95

\begin{abstract}
This paper aims to explore how a transfer effect and an unmarkedness effect interact in Taiwanese EFL (English as a foreign language) learners' English production, using an Optimality Theoretic approach. My focus is the nasals in syllable coda positions. This study carried out an English production experiment, in which sixty-two participants took part. These participants were 29 Mandarin native speakers (the Mandarin group: MG) and 33 Southern Min native speakers (the Southern Min group: SG). Each participant read 51 test sentences with target coda nasals. There are three major findings in this study: (1) Southern Min speakers have less difficulty with English $/ \mathrm{m} /$ than Mandarin speakers do, suggesting a positive transfer of the first language (L1) phonemic system to the second language (L2); (2) there exists a strong tendency toward unmarked coronal [n] in codas found in both MG and SG and there is no phonological rule of [m] or [ $\mathrm{y}$ ] becoming [n] in these learners' L1, revealing that an unmarkedness effect plays a significant role in shaping the production of interlanguage English with respect to coda nasals; and (3) the preceding two findings reveal that transfer and unmarkedness interact to influence the learning of English coda nasals and that unmarkedness overrides transfer in shaping Taiwanese EFL learners' English interlanguage, leading to the strong preference for unmarked [n] in phonetic representations.
\end{abstract}

Keywords: interlanguage phonology, markedness, L1 transfer, coda nasal, Optimality Theory

\section{Introduction}

This paper aims to explore how a transfer effect and an unmarkedness effect interact in Taiwanese EFL (English as a foreign language) learners' English production, using an Optimality Theoretic approach. ${ }^{1}$ My focus will be the nasals in syllable coda positions. ${ }^{2}$ The transfer effect refers to the fact that speakers' first language (L1) structure influences their second language (L2) production; for example, Taiwanese EFL learners might mispronounce interdental fricative $[\Theta]$ as $[\mathrm{s}]$ in English because their L1 (i.e., Mandarin or Sothern Min) sound system does not contain the sound $[\Theta]$ but $[\mathrm{s}]$. The markedness effect results in a tendency for unmarked sounds (e.g., the unmarked nasal [n] in English, Mandarin, and Southern Min) to replace or be replaced by other sounds (e.g., the marked nasal [m] in English, Mandarin, and Southern Min) in the final or initial position of a syllable (Frisch, 1997; Hsu, 2011; Shattuck-Hufnagel \& Klatt, 1979; Wan, 2002).

Interlanguage phonology has been the focus of much work in second language acquisition (SLA) and related fields over the last sixty years (Altenberg \& Vago, 1987; Aoyama, 2003; Briére, 1966; Broselow et al., 1998; Broselow \& Xu, 2004; Chang, 2002; Corder, 1967; Cortés, 2006; Eckman, 1987; Felix, 1980; Gradman, 1971; Greenberg, 1991; Hsu, 2003; Jakobson, 1941; Johansson, 1973; Koutsoudas \& Koutsoudas, 1983; Lado, 1957; Lehn \& Slager, 1983; Lin, 2002; Major \& Faudree, 1996; Selinker, 1972; Tarone, 1980; Wang, 1995, Wardhaugh,

\footnotetext{
${ }^{1}$ Note that 'Taiwanese learners' is used in this paper to refer to 62 subjects participating in this study. These Taiwanese learners are either native Mandarin or Southern Min speakers in Taiwan.

2 To have a clearer understanding, I center solely on the three nasal segments, $/ \mathrm{m} /, / \mathrm{n} /$, and $/ \mathrm{n} /$, and we do not attempt to extend this study to the segmental co-occurrence restrictions that will be the target of my future study. For example, the /om/ combination is disallowed in Mandarin and Southern Min (Chung, 2002).
} 
1970; White, 1987; Wode, 1976; to mention just a few). These studies have demonstrated that either the transfer effect or the markedness effect plays a significant role in SLA. To be precise, some claim that the influence of L1 structure was much stronger in phonology, in particular, the transfer of pronunciation of the L1 sounds to L2 acquisition, than in other components of grammar; some argue, on the other hand, that less marked structures are learned more easily than marked structures. Within the fairly extensive literature, we can see a treatment of the dichotomy of transfer versus markedness in SLA. But how the transfer and the markedness effects interplay to shape interlanguage phonology has received relatively little attention. This present study aims to begin to fill this gap by focusing on English coda nasals made by Mandarin and Southern Min native speakers in Taiwan. The work in this study is hoped to be one step towards deeply understanding the learning process of a foreign language (FL) or a second language. Specific research questions are addressed as follows:

a. Do the transfer and markedness effects interact with each other in the course of learning an FL or L2 with respect to nasals in the coda position?

b. Given that the two effects do affect the process of learning FL or L2 simultaneously, what will the interlanguage production 'look like'?

c. How does the unmarkedness effect influence FL or L2 learning with the transfer effect, or vice versa?

This study consists of one English production experiment which examined the production of English coda nasals by native Southern Min and Mandarin speakers to investigate how learners' production of L2 segments is influenced by both the learners' L1 and the markedness effect. Southern Min and Mandarin are generally defined as dialects of Chinese, which are spoken in Taiwan, according to the criterion of "political and social conventions." Like English, Southern Min is a three-nasal-coda system language, whereas Mandarin is a two-nasal-coda system language. An output-oriented and constraint-based theory, Optimality Theory (OT), will be used as the theoretical framework in this paper to provide insight into how the transfer and markedness effects interact.

Aside from the introductory section, the rest of this paper is organized as follows: Section 2 reviews relevant theories and studies on SLA and Optimality Theory. Section 3 describes the methods of this study. Section 4 illustrates the findings of the English production experiment. These findings of this study are discussed in Section 5. We look into how the OT framework nicely accounts for the sound problems reflected in Taiwanese EFL learners' English production in Section 6. The last section is the conclusion.

\section{Background}

This section introduces some backgrounds about the transfer theory and the markedness theory and reviews related literature on how the modern model, Optimality Theory (OT), explicates the transfer and markedness effects.

\subsection{Optimality Theoretical Framework ${ }^{3}$}

In this section, I will introduce the basic concept Optimality Theory (OT) and the relationship between OT and markedness.

\subsubsection{Basic Concept of OT}

OT, which can be termed a constraint-based and output-oriented approach, is introduced by Prince and Smolensky (1993). OT can be viewed as one of the most important development in generative phonology that restricts phonological grammars to a set of violable ranked constraints.

The basic concept behind OT is that violable constrains are universal and present in every language, whereas their rankings are language-specific, namely differences in the constraint rankings result in cross-linguistic variation. The constraints evaluate potentially infinite candidates generated by a universal function named Generator to pick out the most optimal one, that is, the one having the minimal violation(s).

Now let us focus on the OT architecture. The OT grammar is an input-output device that couples an output form to an input form. To achieve this function, OT grammar must be equipped with three essential components, as listed below.

(1) Components of the OT grammar (Kager, 2001:19):

\footnotetext{
${ }^{3}$ Refer to Sections 1.2 and 1.4 of René Kager's Optimality Theory (2001) for more detailed information about the basic concepts of OT and the architecture of an OT grammar. Also, see Sections 1.3 and 1.5 for the examples of constraint interaction and the interactions of markedness and faithfulness.
} 
LEXICON (Input): stores all lexical forms of morphemes that are input to Gen.

GENERATOR (GEN): generates output candidates for some input, and transfers these to Evaluator.

EVALUATIOR (EVAL): the set of ranked constrains, which evaluates output candidates as to their harmonic values, and single out the harmonic or optimal candidate.

This OT grammar can be schematically represented as in (2). For each possible input, the GEN produces a candidate set, that is, produces all possible structures of the input. The candidate set contains output structures. The EVAL evaluates the candidate set through the particular rankings of the constraints.

(2) Input $\rightarrow$ GEN $\rightarrow$ Candidate set $\rightarrow$ EVAL $\rightarrow$ Optimal candidate

In order to clearly see how this OT mechanism operates, an abstract example is given below. Let us suppose that constraint inventory 'Con' contains Con 1, Con 2, and Con 3. A hypothetical language X is defined by the ranking Con $1 \gg$ Con $2 \gg$ > Con 3. There is a set of possible candidates which include the output structures A-D. These candidates will be evaluated by the ranking Con $1 \gg$ Con $2 \gg$ Con 3. In OT tableaux, constraint violations are given for each output structure. The pointing hand means the optimal output, each asterisk (or star) stands for one violation, and the violation indicated by an exclamation mark '!' refers to fatal (cells to the right of fatal violations are irrelevant for evaluation, thereby being shaded).

Table 1. Language $\mathrm{X}$

\begin{tabular}{|c|c|c|c|}
\hline /Input/ & Con1 & Con2 & Con3 \\
\hline$\Rightarrow \quad A$ & & $*$ & $*$ \\
\hline B & & * & $* * !$ \\
\hline C & & $* * !$ & \\
\hline $\mathrm{D}$ & *! & & \\
\hline
\end{tabular}

A candidate is selected as the winner (i.e., the optimal output) when it incurs the minimal violations. $\mathrm{D}$ is the only candidate that violates the highest-ranked constraint Con1, and, thus, it is fatal, even though it has a smaller number of violations than the other candidates. The other three candidates $\mathrm{A}, \mathrm{B}$, and $\mathrm{C}$ will be further evaluated through the next constraint, Con2. Candidates A and B violate this constraint only once, but $\mathrm{C}$ does so twice and subsequently it is fatal. Then, A and B move to the next constraint, Con3, to be evaluated. B invites two violations of Con3, but A does so only once, and so A is the optimal candidate.

\subsubsection{OT and Markedness}

The concept of markedness is modified in OT (Prince \& Smolensky, 1993). Kager (2001:2-3) points out that in Principles-and-Parameters Theory (Chomsky, 1965, 1981; Chomsky \& Halle, 1968), markedness has no substantive place in grammar, but it only serves as a function to evaluate whether a structure or a grammar is basic/core or complex/peripheral (see Section 2.3 for the basic notion of markedness). Comparatively, OT grants markedness an essential place in grammar and treats markedness principles as the substantial elements of grammars. More precisely, the idea of markedness is defined in terms of universal constraints, which is built into grammar in every language to become part of the grammar, and so that is why Major (1998) describes that this optimality theoretical model is often thought of as the latest development in the markedness theory.

OT contains two conflicting forces: Markedness and Faithfulness. Markedness exerts pressure toward unmarked structures and attenuates marked forms as much as possible, whereas Faithfulness exerts pressure toward the preservation of lexical contrasts. In a sense, an unmarked structure surfaces in the phonetic representation only if the markedness force becomes visible and the influence of Faithfulness is absent. For instance, the constraint *VOICED-CODA prohibits a syllable from ending with voiced obstruents; in other words, it bans a marked voiced obstruent in coda positions (Broselow et al, 1998; Broselow \& Xu, 2004; Kager, 2001). Such a constraint should be ranked higher, such that it becomes visible, namely its effect works.

As argued in McCarthy and Prince (2004), unmarked structures will emerge in certain circumstances when it is the lower-ranked markedness constraints but not higher-ranked faithfulness ones which make a crucial choice. ${ }^{4}$ McCarthy and Prince (2004) investigate the structure of reduplicative morphemes in Nooka. Their study shows that the unmarked syllabic structure CV has been observed in the reduplicant of Nooka. This unmarked structure

\footnotetext{
${ }^{4}$ In other words, the influence of the lower-ranked markedness constraints is present, leading to the emergence of the
} unmarked structures. At the same time, the constraints, which exert pressure toward marked structures, are suppressed. 
appears under this ranking, NO-CODA > MAX (Markedness >> Faithfulness), whereby more codas are strictly prohibited from the occurrence in the output.

In second language learning (SLA), Broselow et al (1998) have demonstrated that the unmarkedness effect is often visible in SLA, leading to the occurrence of unmarked patterns. ${ }^{5}$ They argue, based on OT, that the unmarkedness effect becomes visible when the influence of lower-ranked markedness constraints is present, for example, NO VOICED OBS CODA $\gg$ MAX(C), DEP(V) $\gg$ IDENT(VOI) $\gg$ NO OBS CODA (see Table 3 in Section 2.3).

There exists a general tendency that coronals (e.g, n) are statistically less marked than dorsals (e.g., $\mathrm{y}$ ) and labials (e.g., m). Prince and Smolensky (1993) and Lombardi (2001) succinctly explain the linguistic phenomenon by using the OT model. They put forth three OT constraints, * $\mathrm{LAB}$, *DORS, and *COR, and formalize their relative marked relation as *LAB, *DORS $>$ *COR. The three constraints are defined as follows:

(3) Place markedness subhierarchy:

*LAB, *DORS $\gg *$ COR

* LAB: Any nasal with [labial] place feature is banned.

* DORS: Any nasal with [dorsal] place feature is banned.

* COR: Any nasal with [coronal] place feature is banned.

The ranking among the three places in (3) shows that labial and dorsal sounds are more strictly prevented from surfacing than coronals. Using different rankings of the OT constraints to explain Place markedness hierarchies has been well documented in a good many previous studies (e.g., Alderete, 2004; Beckman, 2004; de Lacy, 2004; Hume \& Tserdanelis, 2002; Iverson \& Lee, 1995; Lombardi, 2002, 2004; Prince, 1997a, b, 1999).

Furthermore, as to marked elements in codas, Zoll (2004) put forth Positional Markedness, of which the basic assumption is that a marked structure has a more limited distribution than an unmarked structure does. ${ }^{6}$ Positional Markedness demands that marked structures must or cannot occur in certain positions (Itô \& Mester, 1994; Steriade, 1997; Zoll, 1996, 1997). For instance, the negative constraint, NoCODA(Labial), disallows labial consonants in coda position (Zoll, 2004:365); this constraint excludes forms that are both marked and in a weak position like codas. Consider the data in Table 2 provided in Zoll (2004):

Table 2. Hypothetical /pum-sa/ $\rightarrow$ [pun.sa] (Zoll, 2004:366)

\begin{tabular}{|c|c|c|c|c|}
\hline /pum-sa/ & NOCODA(LAB) & IDENT(SEG) & NOCODA & *LABIAL \\
\hline a. pum.sa & $* !(\mathrm{m})$ & & $*(\mathrm{~m})$ & $* *(\mathrm{~m}, \mathrm{p})$ \\
\hline b. pun.sa & & $*(\mathrm{n})$ & $*(\mathrm{n})$ & $*(\mathrm{p})$ \\
\hline c. tun.sa & & $* * !(\mathrm{t}, \mathrm{n})$ & $*(\mathrm{n})$ & \\
\hline
\end{tabular}

In Table 2, Candidate (a) is ruled out due to its first syllable ending in a bilabial nasal. Candidate (c) has more violations of IDENT(SEG) than Candidate (b), thus being excluded. Here we can see the conflicting relation between Faithfulness and Markedness as well as the relative ranking between Positional Markedness and markedness, in addition to the strict prohibition of [m] from surfacing in the coda. ${ }^{7}$

As presented above, using faithfulness and markedness constraints and their relative hierarchy, OT succeeds in succinctly explaining whether or not the markedness effect emerges in a particular language or in SLA. In terms of OT, the unmarkedness effect emerges when the influence of lower-ranked markedness constraints is present. With OT's treatment of the unmarkedness effect, I will delve into how OT straightforwardly elucidates the tendency toward the unmarked [n] in the coda position in Taiwanese learners' L2 English production found in

\footnotetext{
5 Broselow et al (1998) studied the forms ending with obstruents produced by Mandarin speakers and found two tendencies toward unmarked patterns: final voiced obstruents tend to be devoiced, and the forms tend to be produced as bisyllabic (e.g., $/ \mathrm{vI} / \rightarrow[\mathrm{vIg} \partial])$.

${ }^{6}$ Zoll (2004:376) concludes that "Positional Faithfulness is concerned only with preserving input/output correspondence in strong positions...Without Positional Markedness there is no way to limit derived marked structure to exclusively strong positions".

${ }^{7}$ IDENT(SEG) ranked above *LABIAL prevents onset labial consonants from neutralization.
} 
this study.

\subsubsection{Why OT?}

OT is used as a theoretical framework in this study because OT is beneficial to elucidating the results of this study in several ways. For one thing, OT can provide a unified mechanism (i.e., a set of universal constraints and their relative rankings) to succinctly explain the two different effects (i.e., the transfer and unmarkedness effects), which exert their influence on the interlanguage English. In this view, OT builds a bridge between the transfer effect and the unmarkedness effect. This in turn allows us to directly see how the transfer and unmarkedness effects interplay to shape the interlanguage English coda nasals with a set of universally violable constraints (since the distinct effects can be formally related within the OT framework). Therefore, the unified mechanism makes the correlation between the different effects visible. Lastly, OT captures the dynamic interaction between the L1 and interlanguage grammars in a parallel fashion or in one step, by showing the hierarchical relations among different constraints.

OT assumes that every language (in effect every grammar) comprises and is subject to two conflicting forces that are realized by constraints. The two main forces are Markedness and Faithfulness, as mentioned in Section 2.1.2. Markedness prefers unmarked structures and minimizes marked forms; however, Faithfulness prefers to preserve lexical contrasts (Kager, 2001). OT grants markedness an essential place in grammar and treats markedness principles as the substantial elements of grammars. That is why Broselow and Xu (2004:136) argue that because OT assumes "a set of universal markedness constraints as part of the grammar of every language," it provides "a way to build markedness principles into the acquisition process."

An unmarked structure surfaces in the phonetic representation only if the markedness force becomes visible and the influence of Faithfulness is absent (Broselow et al, 1998; Broselow \& Xu, 2004; Kager, 2001; McCarthy \& Prince, 2004). As argued in McCarthy and Prince (2004), unmarked structures will emerge in certain circumstances when it is the lower-ranked markedness constraints but not higher-ranked faithfulness ones which make a crucial choice. In other words, the influence of the lower-ranked markedness constraints is present, leading to the emergence of the unmarked structures. At the same time, the constraints, which exert pressure toward marked structures, are suppressed. Therefore, the markedness effect can receive a straightforward explanation in terms of OT.

When it comes to the transfer effect, OT decodes it as the change or readjustment of the constraint ranking. More precisely, OT interprets the transfer effect as the transfer of the constraint ranking(s) of FL/L2 learners' L1 to interlanguage.

Therefore, it will be very interesting to see how OT accounts for the interaction of the transfer and markedness effects nicely.

\subsection{Transfer Account}

Since Lado (1957), the influence of L1 over L2 acquisition has been the focus of more and more literature on SLA. The ideas and notions of the transfer of L1 to L2 have been accumulated into a theory, called Contrastive Analysis Hypothesis (CAH). In nature, $\mathrm{CAH}$ is in the position that the areas of difficulty in learning $\mathrm{L} 2$ are traceable to learners' native language. That is, L2 learners' errors are attributed to the differences between L1 and L2; comparatively speaking, the similarities between L1 and L2 will be easy for learners to learn. The relative ease of learning similar structures between L1 and L2 is a result of the positive transfer of L1 structure to L2; the difficulties, negative transfer.

The transfer of L1 to L2 has been demonstrated in many experimental studies (Chiang, 1979; Inagaki, 1997; Koda, 1990; Montrul, 1997; Palmberg, 1987; Sassoon, 1995; Thompson, 1991). Even nowadays, the commonly held belief is that learners' pronunciation of L2 sounds is influenced to a great extent by negative transfer from L1; that is, L2 learners attempt to use L1 sound patterns to replace those of L2 (Aoyama, 2003; Cortés, 2006; Flege \& Wang, 1989; Lai, 2000; Liao, 1998; Su, 1996; Wei, 1997). For instance, Japanese learners are inclined to replace the voiceless dental fricative with voiceless alveolar stop [t] and the voiced dental fricative with the voiced alveolar stop [d]; this is accounted for by the transfer of Japanese phonemic system to English because Japanese does not permit both the voiceless and voiced dental fricatives (Bada, 2001).

In OT, the transfer is interpreted as the change or readjustment of constraint ranking, which is not far from the transfer proposals in spirits. For instance, Monahan (2001) reinterpreted the traditional transfer process as the effect of the L1 constraint ranking on L2 when Brazilian Portuguese (BP) learns English. Phonologically, BP is very restrictive in its syllable structure and permits only $[\mathrm{s}]$ and $[\mathrm{r}]$ in the coda position. Monahan found that the BP speakers wrongly pronounced 'clan' in English as [ $\left.\mathrm{k}^{\mathrm{h}} l \mathfrak{x}\right]$ or 'transport' as [ $\mathrm{t}^{\mathrm{h}}$ ræ.spor] where coda nasals were 
dropped and the [+nasal] feature then spreads to the preceding vowel. Monahan explained this mispronunciation as a transfer of high-ranked constraints in Brazilian Portuguese CODA-COND/*COMPLEX CODA into interlanguage phonology. ${ }^{8}$ Thus, the interlaguage ranking for such outputs as $\left[\mathrm{k}^{\mathrm{h}} l æ\right]$ or $\left[\mathrm{t}^{\mathrm{h}} \mathrm{ræ}\right.$.spor] is CODA-COND/*COMPLEX CODA > MAX-IO(NASAL) > IDENT-IO(NASAL) > *VNASAL, suggesting that the $\mathrm{L} 1$ constraint ranking is transferred into $\mathrm{L} 2$ grammar.

Based on the transfer effect, it should be expected that learners' L1 will influence their L2 learning.

\subsection{Markedness Account}

Apart from the transfer account, the markedness effect is another important factor in governing SLA, as claimed in many studies (e.g., Broselow \& Xu, 2004; Eckman, 1987; Greenberg, 1991; Jakobson, 1941; Major \& Faudree, 1996; White, 1987).

Greenberg $(1974,1980)$ argued that markedness and unmarkedness are treated as relative terms. The more frequent sounds in world languages the less marked. For instance, among the three nasals [m, n, $\mathrm{p}]$, the coronal one is the most unmarked, since wherever there are $[\mathrm{m}, \mathrm{p}]$ in a language, there is $[\mathrm{n}]$, but not vice versa. Jakobson is a pioneer to observe the phenomenon of the linguistic markedness. Jakobson (1941) found that certain linguistic elements of a language are less marked than others. Unmarked elements are universally present in most languages, while marked elements occur only in, relatively speaking, a few languages. Moreover, unmarked elements tend to be more frequent than marked ones within a particular language. For example, a study on phoneme frequencies in English shows that coronals are more frequent than labials or velars (Denes, 1963).

Eckman (1987) is a pioneer in introducing the notion of markedness into SLA. Eckman proposes Markedness Differential Hypothesis (MDH). This hypothesis predicts that L2 areas that are more marked than L1 will be more difficult to learn, but if the target in L2 is unmarked, L2 learners will have no difficulty in learning it. More recently, in terms of markedness, some studies point out that errors are more likely to be unmarked outcomes and this phenomenon is termed as a result of the emergence of the unmarkedness effect (e.g., Broselow et al., 1998).

Very recently, there has been a growing interest in studying and deciphering the markedness effect on SLA within the OT framework. Broselow et al (1998) investigated the forms with final obstruents produced by Mandarin speakers. They found that final voiced obstruents tended to be devoiced (e.g., /b/ $\rightarrow[\mathrm{p}]$ ). They concluded that because voiceless obstruents are less marked than voiced ones and thus the unmarkedness effect was attested in SLA. Broselow et al (1998) claimed that this pattern in SLA was a result of the emergence of the unmarkedness, which was a result of the high-ranked markedness constraints. A constraint ranking NO VOICED OBS CODA $\gg \operatorname{MAX}(\mathrm{C}), \operatorname{DEP}(\mathrm{V}) \gg \mathrm{IDENT}(\mathrm{VOI}) \gg$ NO OBS CODA is provided as an example and its tableaux are shown below.

Table 3. Mandarin Subjects Favoring Devoicing (Broselow et al, 1998:276) ${ }^{9}$

\begin{tabular}{|c|c|c|c|c|}
\hline input:/vlg/ & $\begin{array}{c}\text { NO VOICED OBS } \\
\text { CODA }\end{array}$ & MAX(C), DEP(V) & IDENT(VOI) & NO OBS CODA \\
\hline a. vlk & & & $*$ & $*$ \\
\hline b. vlg & $* !$ & & & $*$ \\
\hline c. vl & & $* !$ & & \\
\hline d. vl.gə & & $* !$ & & \\
\hline
\end{tabular}

Based on the markedness effect, it should be predicted that unmarked nasals in coda positions tend to appear in English interlanguage phonology made by Taiwanese EFL learners.

\subsection{Nasal Distribution of Coda in English, Mandarin, \& Southern Min}

8 The constraint CODA-COND/*COMPLEX CODA refers to a coda condition which prohibits complex codas from occurring in phonetic representations. The constraint is ranked higher in BP but lower in English.

9 NO VOICED OBS CODA means voiced obstruent consonants which are not allowed in the coda position; MAX(C) and $\operatorname{DEP}(\mathrm{V})$ mean that the output consonant(s) or vowel(s) can correspond to the input one(s); IDENT(VOI) refers to the fact that the input and the output are the same in the voice feature; NO OBS CODA refers to obstruent consonants which are not allowed in the coda position. 
Southern Min, similar to English, allows nasal segments $/ \mathrm{m} /, \mathrm{n} /$, and $/ \mathrm{y} /$ in the syllable coda position, whereas Mandarin Chinese only allows $/ \mathrm{n} /$ and $/ \mathrm{y} /$ in the coda position, as indicated in Table 4:

Table 4. Nasals inventory in codas in Mandarin, Southern Min, and English

\begin{tabular}{|c|c|c|c|}
\hline Coda Nasals & English & Mandarin & Southern Min \\
\hline$/ \mathrm{n} /$ & Yes & Yes & Yes \\
\hline$/ \mathrm{n} /$ & Yes & Yes & Yes \\
\hline$/ \mathrm{m} /$ & Yes & No & Yes \\
\hline
\end{tabular}

The data in Table 4 show that Southern Min allows bilabial $/ \mathrm{m} /$ in the coda position, while Mandarin does not. According to the phoneme transfer account (Lado, 1957; Tarone, 1980; Wardhaugh, 1970), it should be expected that English coda $/ \mathrm{m} /$ is more difficult for Mandarin speakers to learn than for Southern Min speakers. On the other hand, based on the markedness theory, it might be predicted that Taiwanese EFL learners are prone to produce unmarked coronal [n] in English production (since an unmarked sound is easier to learn in light of the markedness account). With the two different predictions, it is of particular interest to explore what predominant error pattern will result from the interaction between the two effects in English coda nasals produced by native Mandarin and Southern Min speakers. It is also quite interesting to explore how the output-oriented model, OT, unifies the two different effects with a set of universally violable constraints and their rankings and sheds more light on understanding the process of FL/L2 learning (i.e., the interaction of the transfer and markedness effects).

\section{Methodology}

This section displays the methods of this study, which conducted an experiment centered on Taiwanese learners' English production of coda nasals, $/ \mathrm{m} /, / \mathrm{n} /$, and $/ \mathrm{y} /$.

\subsection{Subjects}

In the English production experiment, 62 non-native English speakers were recruited from two L1 backgrounds, Mandarin and Southern Min, and paid \$30 upon completion of the experiment. The Freshman English teachers at either Shih Chien University, or National Kaohsiung Hospitality College, or National Kaohsiung Normal University informed their students (studying the Freshman English) of the experiment information. All of the participants learned English as a foreign language. To date, they have been learning English for more than eight years. All of them were English learners at a basic level based on the General English Proficiency Test (GEPT) (i.e., they passed the basic level of GEPT). Their ages ranged from eighteen to twenty-two. They were categorized into two language groups: Mandarin speakers and Southern Min speakers. ${ }^{10}$ There were 29 participants (16 men and 13 women) for the Mandarin group (MG) and 33 participants (19 men and 14 women) for the Southern Min group (SG).

\subsection{Materials}

There were $51(17 \times 3)$ target sentences along with 38 irrelevant sentences used in the English production experiment. ${ }^{11}$ There are 17 minimal sets, and each set contains three target words with target coda nasals (e.g., pim, pin, and ping). Each target word is imbedded in a sentence, and the sentence is called a target sentence. A test word is arranged to be in the final position of a sentence (e.g., 'Jessica's grandmother has a red dog which is called Pim.') - so there are $51(17 \times 3)$ test sentences in total (refer to Appendix I for all of the target sentences). The irrelevant sentences did not include the target words with coda nasals, for example, 'Chris watered the flowers in his garden in the morning.' 'Tina watered the flowers in her garden in the afternoon.' 'He longs for a chance to visit Taipei.' 'We long for a chance to visit Kaohsiung. 'I do many things to get ready for the day.'

\footnotetext{
${ }^{10}$ Taiwan is a multilingual society and Mandarin is an official language, implying that most of the people in Taiwan (who can speak other dialects of Chinese or languages, in addition to Mandarin) tend to be bilinguals. For example, a Southern Min speaker can speak both Mandarin and Southern Min. Therefore, these subjects, whose first language is Southern Min, have been tested to produce twenty single-syllable words with two nasals in Mandarin, such as $\underline{\text { nien }}$ 'year' and $\underline{\text { nan }}$ 'difficult'. Such a sequence of nasals in a syllable cannot be allowed in Southern Min. If the subjects are unable to produce such words or have greater difficulty with them, implying that they have a heavy Southern Min accent, they will be placed into the Southern Min group. As to these 29 subjects in the Mandarin group, all of them are monolingual.

11 The experimental sentences used in the present study were corrected by six native speakers of English. They were graduate students studying in U.S.A. or in Taiwan.
} 
'Brian drives his daughter to day care.' 'Angela goes to the dining hall for a big breakfast every day.' and 'There are nice fields for playing baseball and new courts for playing tennis.'

There were four major considerations when the test materials were designed. First of all, the position of a target coda nasal in a constituent has been taken into account. If the target nasals were in very different contexts, this might have introduced confounding variables into the study. For example, in the sentence 'My name is...,' the $/ \mathrm{m} /$ at the end of 'name' is prevocalic and would therefore be likely to be resyllabified as an onset to the following vowel. Accordingly, to minimize the effect caused by the position of the nasals in a constituent, each of the target words used in this experiment was arranged in the final position of a sentence. For instance, 'Tina bought ten pairs of dark tan shoes and later bought gum.'

Second, places of articulation of consonants or vowels, which precede the target nasals within a syllable, have been considered. This study purposely designed the test words with an assortment of vowels and onset consonants in three place features (labial, coronal, and dorsal) to eliminate any suspicions for a bias toward a certain place feature. Consider the following target words: ${ }^{12}$

Table 5. Target words

\begin{tabular}{|c|c|c|c|}
\hline & Front & Center & Back \\
\hline \multirow{3}{*}{ High } & pim-pin-ping & & {$\left[p^{h} \sigma m\right]-\left[p^{h} \sigma n\right]-\left[p^{h_{1}}\right]$} \\
\hline & sim-sin-sing & & [sum]-[sun]-[sun] \\
\hline & kim-kin-king & & 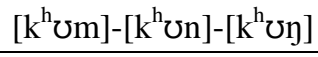 \\
\hline \multirow{3}{*}{ Mid } & same-sane-seng & some-sun-sung & [som]-sone-song \\
\hline & came-cane-[k $\left.\mathrm{k}^{\mathrm{h}} \mathrm{e}\right]$ & gum-gun-[g^ng] & comb-cone-Kong \\
\hline & & & home-hone-Hong \\
\hline \multirow{2}{*}{ Low } & bam-ban-bang & & bomb-[ban]-bong \\
\hline & pam-pan-pang & & {$\left[\mathrm{p}^{\mathrm{h}} \mathrm{am}\right]-\left[\mathrm{p}^{\mathrm{h}} \mathrm{an}\right]-$ pong } \\
\hline
\end{tabular}

The third concern is a priming effect. To avoid the priming effect brought about by preceding sentences, the sentence order should be dealt with carefully. To minimize the priming effect as much as possible, I randomly separated the test materials into three parts, Part A, Part B, and Part C, and divided subjects into three subgroups, Group I, Group II, and Group III. Group I read Part A first, then Part B, and finally Part C; the other two groups did so in a reverse order. The procedure of reading test materials for each group is shown as follows:

\section{Group I: Part A $\rightarrow$ Part B $\rightarrow$ Part C \\ Group II: Part B $\rightarrow$ Part C $\rightarrow$ Part A \\ Group III: Part C $\rightarrow$ Part A $\rightarrow$ Part B}

The last consideration was the subjects' attention. To distract subjects' attention from the target sentences, 38 irrelevant sentences were arranged in this experiment; for example, 'I'm really jealous of his good luck.' and 'Don't touch the pot!'

\subsection{Recording and Measurement}

\subsubsection{Recording}

The recording proceeded in a soundproof computer classroom at National Kaohsiung Normal University. The subjects, who were recorded individually, used Speech Analyzer (speech software) and a noise-filter microphone to directly record their speech on a personal computer.

The experiment sessions lasted over a four-month period. The experiment consisted of two tasks: training and production. All of the subjects were taught the three target nasals $/ \mathrm{m} /, / \mathrm{n} /$, and $/ \mathrm{n} /$ until they could distinguish them from one another in place of articulation. Furthermore, the subjects were taught English vowels to make sure that they did not mispronounce vowels in the target words because if the vowels were mispronounced, the test items would be incomparable. The training task for nasals and vowels lasted for forty minutes monthly.

\footnotetext{
12 The results of this study show no statistical significance in the numbers of errors of coda nasals among the vowels and onset consonants in three place features for both the language groups.
} 
Besides the training of nasals and vowels, a female native speaker of English taught the subjects how to pronounce the test words, such as pam, pan, or pang, in a random order once weekly. The purpose of teaching the test words was to familiarize the subjects with these target words.

As for the production task, the subjects were informed to focus on vowels while producing the test materials. This instruction was to distract subjects' attention from the target nasals. They were aware of the production experiment and told, "It does not matter if you make any errors."

Following this training, each subject was recorded for approximately eighteen minutes once every two months over a period of four months, and, thus, the participants were recorded twice. Only the recording conducted in the fourth month (i.e., the last recording) would be analyzed. Each time before recording, the subjects were presented with the test sentences printed on A4-size paper and were instructed to practice them in the most fluent speaking style. Practicing the test materials took them more than one hour.

\subsubsection{Measurements}

There were two ways to analyze every target nasal: one was by native English speakers' ears and the other was by acoustic measurements. The total number of recorded target characters requiring analysis was 3,162 ( 51 targets $* 62$ subjects).

Three native speakers of English were invited to help with the listening work and paid $\$ 250 .^{13}$ They analyzed every nasal segment independently. If there was little consensus among these native speakers as to which nasal was produced, the controversial nasals would be acoustically reanalyzed by using Speech Analyzer. For example, one analyzed a mispronounced target $/ \mathrm{m} /$ as [n], another as [n], and the other as the one in between [n] or [ $\mathrm{n}]$. Consequently, the total number of recorded target items was 589 in need of analysis using Speech Analyzer. Speech Analyzer with a sampling rate of $16 \mathrm{KHz}$ was utilized. The spectrograms of coda nasals are indicated in Spectrogram A of graph types. The following figures are provided as examples.

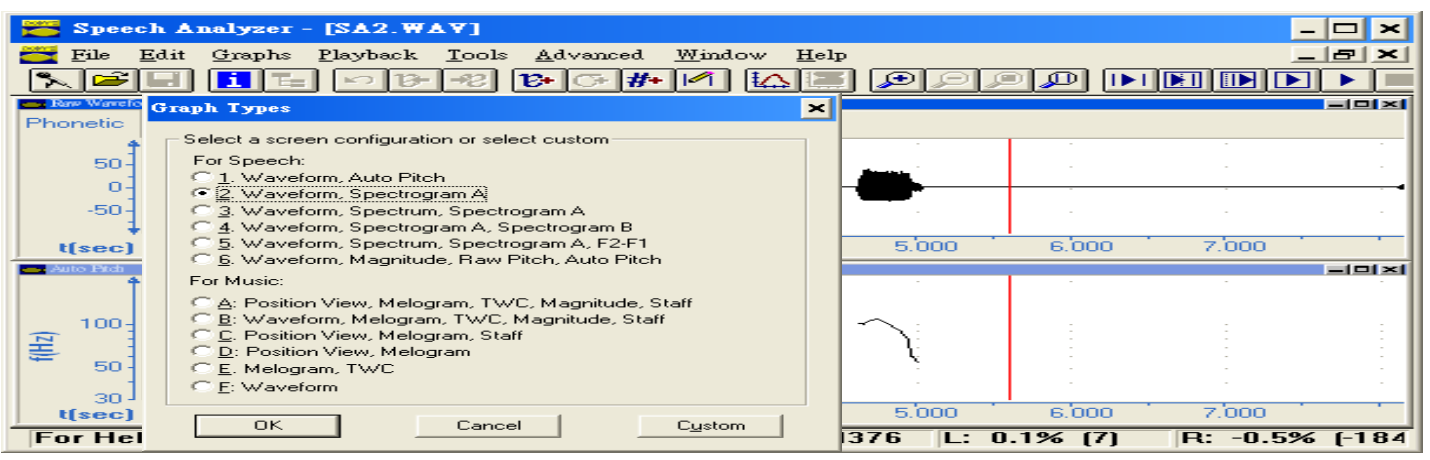

Figure 1. The choice of 'Waveform, Spectrogram A' function of graph types

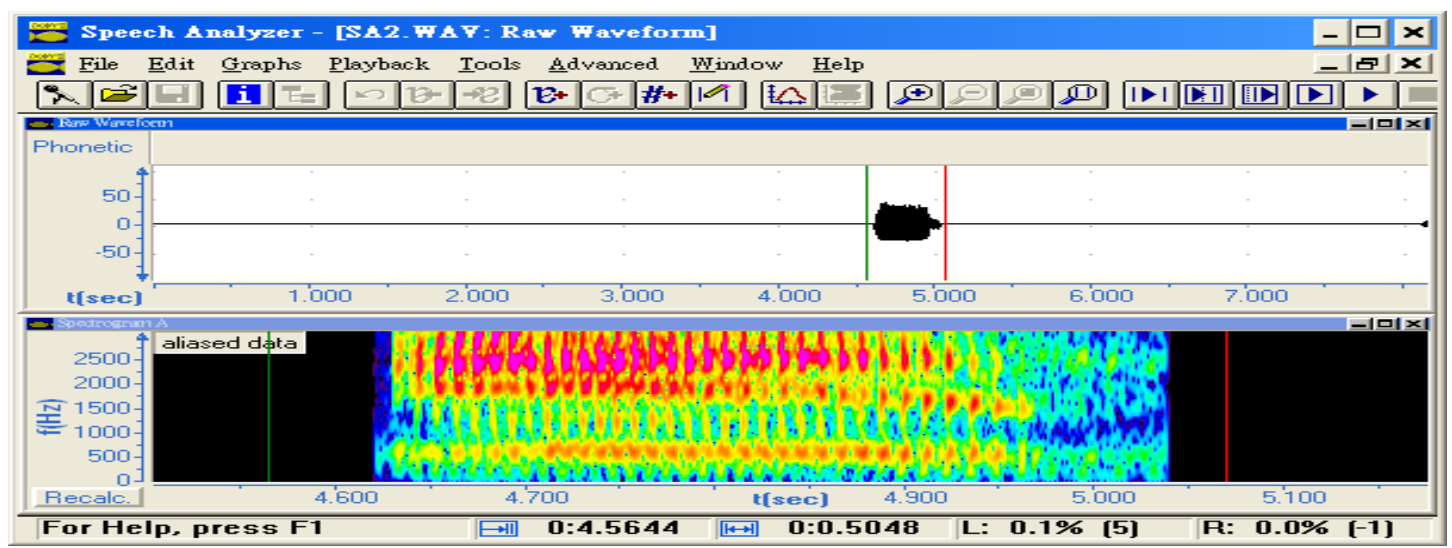

Figure 2. The spectrogram of the sound [æm] made by a male native speaker of English

${ }^{13}$ One was a Ph.D. student in applied linguistics at the National Kaohsiung Normal University in Taiwan. Another completed his master's degree in linguistics at the University of California, Berkeley, U.S.A. and taught English in Taiwan. The other majored in phonetics and was a Ph.D. candidate at the University of California at Los Angeles, U.S.A. 
The transition between a nucleus vowel and its following coda nasal is the target I am focused on; nasals' phonetic characteristics must therefore be identified. That is, recognizing the nasals' phonetic characteristics is very important in order to distinguish the three target nasals in question from one another.

Nasals are voiced stops, and so the vocal folds are vibrating. The nasal sounds $[\mathrm{m}],[\mathrm{n}]$, and $[\mathrm{\eta}]$ are like vowels and approximants in that they can be typified largely in terms of their formant frequencies, but formants for nasals are not as loud as they are in vowels; nasals have a weak formant-like pattern (Ladefoged, 2002; Rogers, 2000; Yavas, 2006). All of the three nasals typically have a very faint and a distinctly very low-frequency F1 (around 200-500 Hz). Another visible one is F3, which is around 2,500-3,000 Hz, whereas there is relatively little energy with respect to F2, generally invisible. ${ }^{14}$

As to transitions between the formants of a nasal sound and those of adjacent sounds (Ladefoged, 2002; Rogers, 2000; Yavas, 2006), for the bilabial nasal $/ \mathrm{m} /$, the second formant lowers in frequency, leading to the result of a transition pointing down. For the alveolar nasal $/ \mathrm{n} /$, its transition of the second formant is level and the third one is slightly higher. The $/ \mathrm{y} /$ is far more distinct. Its transition of the second formant points up merging with that of the third formant. This pattern characterized the nasal consonants (Ladefoged, 2002; Rogers, 2000; Yavas, 2006).

The analyzed results were computed by means of SPSS 12.0 to further make visible differences in the numbers of errors among error patterns and between the two language groups. For each speaker, I tallied the sum and percentages of wrong outputs and mispronounced inputs with respect to coda nasals. The numbers of errors were computed by using Independent-Samples T-test and one-way ANOVA of SPSS 12.0.

\section{Results}

This section presents the results of the English production experiment. The analysis is based on a total of 3,162 outputs (51 test sentences $\times 62$ participants).

\subsection{The Numbers of Mispronounced Inputs}

This subsection displays the error rates of inputs of English coda nasals produced by the Mandarin group (MG) and the Southern Min group (SG).

The numbers and the percentages of errors for each group are shown in Table 6. In Table 6, the arrow ' $\rightarrow$ ' refers to 'becomes'. For example, ' $/ \mathrm{n} / \rightarrow[\mathrm{m}] /[\mathrm{n}]$ ' is read as 'Alveolar nasals are mispronounced as bilabial or velar nasals.'

In Table 6, we can see that the Mandarin speakers almost made more errors for each error pattern than the Southern Min speakers did (MG: 30.09\% > SG: 25.37\%). The total numbers of errors were sent to an Independent-Samples T-test, indicating that the numbers of errors are significantly different between SG and MG $(t(29,33)=2.104, p=.040)$ (see Table 7). ${ }^{15}$ These statistical results suggest that the Mandarin speakers have more difficulty learning English nasals in the coda position than the Southern Min speakers do.

Table 6. The numbers and percentages of errors of English coda nasals made by MG and SG

\begin{tabular}{cccccc}
\hline $\begin{array}{c}\text { Language } \\
\text { Groups }\end{array}$ & $\begin{array}{c}\text { Number of } \\
\text { Subjects }\end{array}$ & $/ \mathbf{m} / \rightarrow[\mathbf{n}] /[\mathbf{n}]$ & $/ \mathbf{n} / \rightarrow[\mathbf{m}] /[\mathbf{n}]$ & $/ \mathbf{n} / \rightarrow[\mathbf{m}] /[\mathbf{n}]$ & Total \\
\hline$\underline{\text { Mandarin }}$ & $\underline{\mathbf{2 9}}$ & 222 & 97 & 126 & 445 \\
$\underline{(\mathbf{M G})}$ & & $(45.03 \%)$ & $(19.68 \%)$ & $(25.56 \%)$ & $(30.09 \%)$ \\
\hline$\underline{\text { Southern Min }}$ & $\underline{\mathbf{3 3}}$ & 171 & 108 & 148 & 427 \\
$\underline{(\mathbf{S G})}$ & & $(30.48 \%)$ & $(19.25 \%)$ & $(26.38 \%)$ & $(25.37 \%)$ \\
\hline
\end{tabular}

\footnotetext{
${ }^{14}$ The F2 locus frequency for alveolar stops is at about 1,800 Hz and for bilabials at $720 \mathrm{~Hz}$, whereas velars have a higher F2 locus at 3,000 Hz. In brief, "labials have a low-frequency locus, alveolars a middle-level locus, and velars a somewhat higher one" (Johnson, 1997:136).

15 The .05 level of significance is selected for the T-test and one-way ANOVA in this study.
} 
Table 7. $t$ value: total numbers of errors

\begin{tabular}{|c|c|c|c|c|c|c|}
\hline $\begin{array}{c}\text { Language } \\
\text { Groups }\end{array}$ & $\mathbf{N}$ & Mean & $\begin{array}{c}\text { Std. } \\
\text { Deviation }\end{array}$ & $\mathbf{t}$ & df & Sig. \\
\hline $\begin{array}{c}\text { Mandarin } \\
\text { (MG) }\end{array}$ & 29 & 15.34 & 4.768 & \multirow{2}{*}{2.104} & \multirow{2}{*}{60} & \multirow{2}{*}{.040} \\
\hline $\begin{array}{l}\text { Southern Min } \\
\text { (SG) }\end{array}$ & 33 & 12.94 & 4.235 & & & \\
\hline
\end{tabular}

Although the Mandarin speakers made more errors than the Southern Min speakers did, the data in Table 6 indicate that similar overall patterns of errors were found for both of them. That is, for both MG and SG, input $/ \mathrm{n} /$ incurred the fewest errors in the coda position, and $/ \mathrm{m} /$ the most errors, with $/ \mathrm{n} /$ somewhere in between $(/ \mathrm{n} /<$ $/ \mathrm{y} /</ \mathrm{m} /$ ). The numbers of errors were submitted to a one-way ANOVA. As indicated in Table 8, statistically significant differences are found in the numbers of errors among the three patterns of errors for both groups (Mandarin: $F(2,84)=35.257, p=.000$; Southern Min: $F(2,96)=5.893, p=.004)$. The results suggest that the alveolar $/ \mathrm{n} /$ is the easiest for both language groups to learn and the bilabial $/ \mathrm{m} /$ is the most difficult.

Table 8. One-way ANOVA

\begin{tabular}{|c|c|c|c|c|c|}
\hline $\begin{array}{l}\text { Language } \\
\text { Group }\end{array}$ & $\begin{array}{c}\text { Input Coda Nasals } \\
(/ \mathbf{m} /, / \mathbf{n} /, / \mathbf{y} /)\end{array}$ & df & $\mathbf{F}$ & MSE & Sig. \\
\hline $\begin{array}{l}\text { Mandarin } \\
\text { (MG) }\end{array}$ & $\begin{array}{l}\text { Between Groups } \\
\text { Within Groups }\end{array}$ & $\begin{array}{c}2 \\
84\end{array}$ & 35.257 & $\begin{array}{c}147.598 \\
4.186\end{array}$ & .000 \\
\hline $\begin{array}{l}\text { Southern } \\
\text { Min (SG) }\end{array}$ & $\begin{array}{l}\text { Between Groups } \\
\text { Within Groups }\end{array}$ & $\begin{array}{c}2 \\
96\end{array}$ & 5.893 & $\begin{array}{c}30.798 \\
5.226\end{array}$ & .004 \\
\hline
\end{tabular}

As to bilabial $/ \mathrm{m} /$, the data in Table 6 show that the $/ \mathrm{m} /$ receives a higher error rate from MG than that from SG (MG: $45.03 \%$ > SG: 30.48\%). The numbers of $/ \mathrm{m} /$-to-[n]/[n] errors were sent to the Independent-Samples T-test. As shown in Table 9, there is a significant difference in the number of $/ \mathrm{m} /$-to-[n]/[n] errors between $\mathrm{SG}$ and MG $(t(29,33)=4.147, p=.000)$, whereas the numbers of errors for the other error patterns do not differ significantly between SG and MG $(p>.05)$. The results suggest that the Mandarin speakers have greater difficulty with English bilabial $/ \mathrm{m} /$ in the coda position than the Southern Min speakers do because coda $/ \mathrm{m} /$ does not exist in Mandarin.

Table 9. $t$ value

\begin{tabular}{|c|c|c|c|c|c|c|c|}
\hline & $\begin{array}{c}\text { Language } \\
\text { Groups }\end{array}$ & $\mathbf{N}$ & Mean & $\begin{array}{c}\text { Std. } \\
\text { Deviation }\end{array}$ & $\mathbf{t}$ & df & Sig. \\
\hline \multirow{2}{*}{$\begin{array}{c}/ \mathbf{m} / \rightarrow[\mathbf{n}] / \\
{[\mathbf{y}]}\end{array}$} & $\begin{array}{c}\text { Mandarin } \\
\text { (MG) }\end{array}$ & 29 & 7.66 & 2.288 & \multirow{2}{*}{4.147} & \multirow{2}{*}{60} & \multirow{2}{*}{.000} \\
\hline & $\begin{array}{c}\text { Southern Min } \\
\text { (SG) }\end{array}$ & 33 & 5.18 & 2.391 & & & \\
\hline \multirow{2}{*}{$\begin{array}{c}/ \mathbf{n} / \rightarrow[\mathrm{m}] / \\
{[\mathrm{y}]}\end{array}$} & $\begin{array}{c}\text { Mandarin } \\
\text { (MG) }\end{array}$ & 29 & 3.34 & 1.675 & \multirow{2}{*}{.155} & \multirow{2}{*}{60} & \multirow{2}{*}{.878} \\
\hline & $\begin{array}{c}\text { Southern Min } \\
\text { (SG) }\end{array}$ & 33 & 3.27 & 1.957 & & & \\
\hline \multirow{2}{*}{$\begin{array}{c}/ \mathbf{y} / \rightarrow[\mathbf{n}] / \\
{[\mathbf{m}]}\end{array}$} & $\begin{array}{c}\text { Mandarin } \\
\text { (MG) }\end{array}$ & 29 & 4.34 & 2.126 & \multirow{2}{*}{-.289} & \multirow{2}{*}{60} & \multirow{2}{*}{.773} \\
\hline & $\begin{array}{c}\text { Southern Min } \\
\text { (SG) }\end{array}$ & 33 & 4.52 & 2.464 & & & \\
\hline
\end{tabular}


In sum, as to the three target nasals in the codas, the Mandarin and Southern Min speakers are more likely to mispronounce bilabial $/ \mathrm{m} /$, implying that the $/ \mathrm{m} /$ is the most difficult for both of them. The Mandarin speakers, however, have greater difficulty with the coda $/ \mathrm{m} /$ in English than the Southern Min speakers do, since Mandarin does not allow the bilabial nasals in the syllable-final position, but Southern Min does.

\subsection{The Numbers of Wrong Outputs}

This subsection exhibits the numbers of wrong outputs of English coda nasals made by the Mandarin and Southern Min speakers.

The data in Table 10 show that both MG and SG mistakenly produced coda nasals as [n] at the highest rate, followed by $[\mathrm{n}]$, and then $[\mathrm{m}]([\mathrm{n}]>[\mathrm{n}]>[\mathrm{m}])$. In other words, the error rates show a tendency for $[\mathrm{n}]$ to replace $\mathrm{m} / \mathrm{or} / \mathrm{y} /$ in both language groups. The numbers of errors were submitted to a one-way ANOVA. As indicated in Table 11, the numbers of errors are significantly different among the three patterns of errors for both groups (Mandarin: $F(2,84)=90.539, p=.000$; Southern Min: $F(2,96)=58.825, p=.000)$; stated differently, [n] shows a significant difference in replacing $/ \mathrm{m} /$ or $/ \mathrm{y} /$ for both $\mathrm{MG}$ and $\mathrm{SG}$.

Table 10. The numbers and percentages of wrong outputs regarding English coda nasals

\begin{tabular}{|c|c|c|c|c|}
\hline \multirow{2}{*}{$\begin{array}{l}\text { Language } \\
\text { Groups }\end{array}$} & \multirow{2}{*}{$\begin{array}{l}\text { Number of } \\
\underline{\text { Subjects }} \\
\underline{\text { (persons) }}\end{array}$} & \multicolumn{3}{|l|}{ Error Patterns } \\
\hline & & $/ \mathbf{n}, \mathbf{y} / \rightarrow[\mathbf{m}]$ & $/ \mathbf{m}, \mathbf{y} / \rightarrow[\mathbf{n}]$ & $/ \mathbf{m}, \mathbf{n} / \rightarrow[\mathbf{y}]$ \\
\hline$\frac{\text { Mandarin }}{\text { (MG) }}$ & $\underline{29}$ & $23(2.33 \%)$ & $270(27.38 \%)$ & $152(15.42 \%)$ \\
\hline$\frac{\text { Southern }}{\text { Min (SG) }}$ & $\underline{\mathbf{3 3}}$ & $31(2.76 \%)$ & $240(21.39 \%)$ & $156(13.90 \%)$ \\
\hline
\end{tabular}

Table 11. One-way ANOVA

\begin{tabular}{llcccc}
\hline $\begin{array}{c}\text { Language } \\
\text { Group }\end{array}$ & \multicolumn{1}{c}{$\begin{array}{c}\text { Output Coda Nasals } \\
([\mathrm{m}],[\mathbf{n}],[\mathbf{n}])\end{array}$} & df & F & MSE & Sig. \\
\hline Mandarin & Between Groups & 2 & 90.539 & 526.287 & .000 \\
& Within Groups & 84 & & 5.813 & \\
\hline Southern & Between Groups & 2 & 58.825 & 335.162 & .000 \\
Min & Within Groups & 96 & & 5.698 & \\
\hline
\end{tabular}

As to $/ \mathrm{m}, \mathrm{y}$--to-[n] errors, the data in Table 12 show that more errors are found for $/ \mathrm{m} /$-to-[n] than for $/ \mathrm{y} /$-to-[n] in both MG and SG. A paired-samples $t$-test analysis shows that for MG, there is a significant difference in the numbers of errors between $/ \mathrm{m} /$-to-[n] and $/ \mathrm{y} /$-to-[n] $(t(29)=3.702, p=.001)$, whereas for SG, the numbers of errors do not differ significantly between the two error patterns $(t(33)=-1.809, p=.080)$ (see Table 13). The differences in error rates between the other error patterns are not significant for both groups $(p>.05)$. These statistical results suggest that in terms of the wrong output [n], the Mandarin speakers deal with the two inputs, $/ \mathrm{m} /$ and $/ \mathrm{y} /$, in the codas differently, since coda $/ \mathrm{m} /$ is not available in the phonemic system of Mandarin, but $/ \mathrm{y} /$ is allowed; however, the Southern Min speakers treat them equally, as both of the nasals are permitted in Southern Min. 
Table 12. The numbers and percentages of wrong outputs of English coda nasals

\begin{tabular}{|c|c|c|c|c|c|c|c|}
\hline \multirow{2}{*}{$\begin{array}{l}\text { Language } \\
\text { Groups }\end{array}$} & \multirow{2}{*}{ 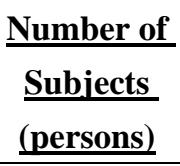 } & \multicolumn{2}{|c|}{ Errors } & \multirow[b]{2}{*}{$/ \mathbf{m} / \rightarrow[\mathbf{n}]$} & \multirow[b]{2}{*}{$/ \mathbf{y} / \rightarrow[\mathbf{n}]$} & \multirow[b]{2}{*}{$/ \mathbf{n} / \rightarrow[\mathbf{y}]$} & \multirow[b]{2}{*}{$/ \mathbf{m} / \rightarrow[\mathbf{\eta}]$} \\
\hline & & $/ \mathbf{n} / \rightarrow[\mathbf{m}]$ & $/ \mathbf{y} / \rightarrow[\mathbf{m}]$ & & & & \\
\hline$\frac{\text { Mandarin }}{\text { (MG) }}$ & $\underline{29}$ & $\begin{array}{c}14 \\
(2.84 \%) \\
\end{array}$ & $\begin{array}{c}9 \\
(1.83 \%) \\
\end{array}$ & $\begin{array}{c}153 \\
(31.03 \%)\end{array}$ & $\begin{array}{c}117 \\
(23.73 \%)\end{array}$ & $\begin{array}{c}83 \\
(16.84 \%)\end{array}$ & $\begin{array}{c}69 \\
(14.00 \%)\end{array}$ \\
\hline \multicolumn{2}{|c|}{$\underline{\text { Total }}$} & \multicolumn{2}{|c|}{$\begin{array}{c}23 \\
(2.33 \%)\end{array}$} & \multicolumn{2}{|c|}{$\begin{array}{c}270 \\
(27.38 \%) \\
\end{array}$} & \multicolumn{2}{|c|}{$\begin{array}{c}152 \\
(15.42 \%) \\
\end{array}$} \\
\hline $\begin{array}{l}\text { Southern } \\
\text { Min (SG) }\end{array}$ & $\underline{\mathbf{3 3}}$ & $\begin{array}{c}18 \\
(1.83 \%) \\
\end{array}$ & $\begin{array}{c}13 \\
(1.32 \%) \\
\end{array}$ & $\begin{array}{c}105 \\
(10.65 \%) \\
\end{array}$ & $\begin{array}{c}135 \\
(13.69 \%) \\
\end{array}$ & $\begin{array}{c}90 \\
(9.13 \%) \\
\end{array}$ & $\begin{array}{c}66 \\
(6.69 \%) \\
\end{array}$ \\
\hline \multicolumn{2}{|c|}{$\underline{\text { Total }}$} & \multicolumn{2}{|c|}{$\begin{array}{c}31 \\
(2.76 \%)\end{array}$} & \multicolumn{2}{|c|}{$\begin{array}{c}240 \\
(21.39 \%)\end{array}$} & \multicolumn{2}{|c|}{$\begin{array}{c}156 \\
(13.90 \%)\end{array}$} \\
\hline
\end{tabular}

Table 13. $t$ values

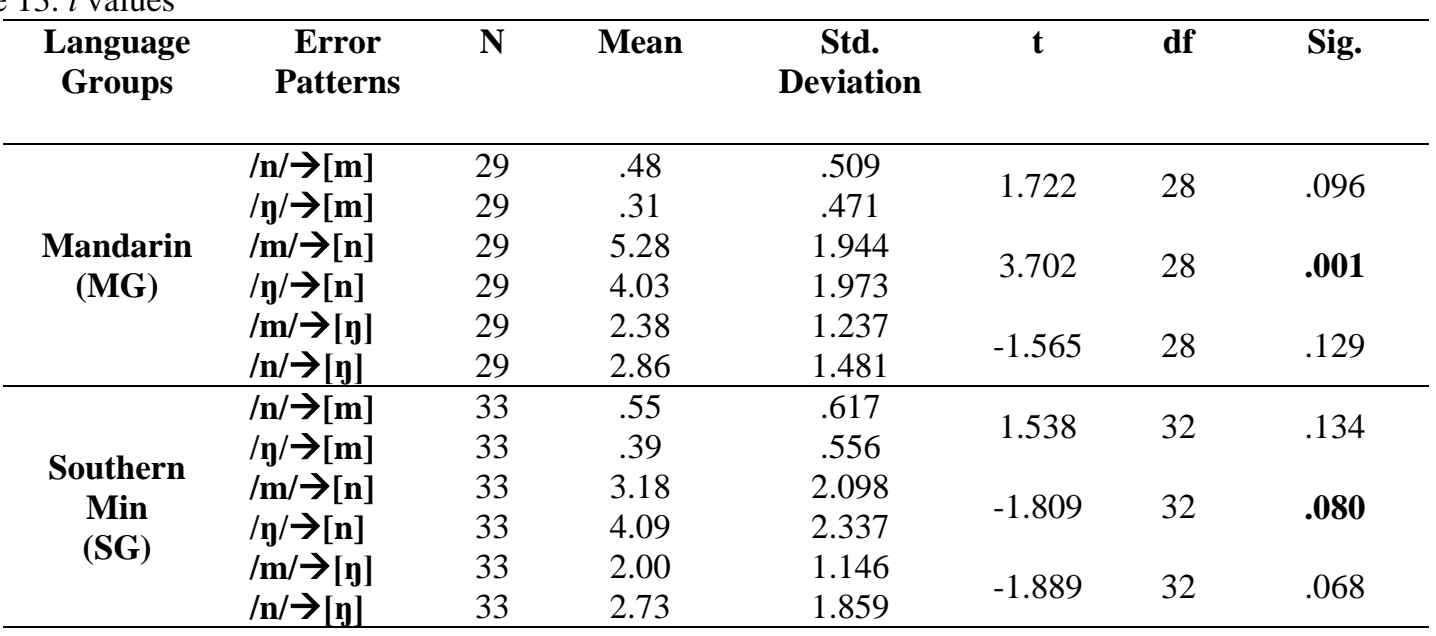

What follows is a discussion of these results.

\section{Discussion}

This section will discuss the results shown previously and looks into how both the transfer and markedness effects govern the formation of Taiwanese EFL learners' interlanguage English with respect to nasals in the codas.

\subsection{Learners' First Language}

To study how Taiwanese EFL learners' L1 affects their interlanguage English of coda nasals, bilabial nasals are the target I focus on because Southern Min permits $/ \mathrm{m} /$ in coda positions, just as English does, while Mandarin disallows it.

As found in Section 4.1, bilabial nasals incur fewer errors from SG than from MG, suggesting that SG has less difficulty with English /m/ than MG does. This result is expected in terms of Contrastive Analysis Hypothesis (CAH). CAH claims that learners' first language influences their learning of an L2 (Aoyama, 2003; Broselow et al., 1983; Cortés, 2006; Inagaki, 1997; Koda, 1990; Lado, 1957; Palmberg, 1987; Sassoon, 1995). CAH predicts that coda bilabial nasals are not available in Mandarin, and, thus, learning $/ \mathrm{m} /$ is difficult for Mandarin speakers; however, the coda $/ \mathrm{m} /$ is allowable in Southern Min, making it easier for Southern Min speakers to learn it. ${ }^{16}$ Therefore, the result in question suggests that the similarity in sound systems between L1 and L2 facilitates learners to pronounce L2 sounds more easily. It seems to be the transfer of Taiwanese EFL learners' L1 to English that causes the relative degree of difficulty in learning English coda $/ \mathrm{m} /$.

However, among the three nasals $/ \mathrm{m}, \mathrm{n}, \mathrm{y} /$, the bilabial $/ \mathrm{m} /$ was found to be mispronounced the most for the

${ }^{16}$ In terms of $\mathrm{CAH}$, the difficulty of producing the coda $/ \mathrm{m} /$ for Mandarin speakers is a result of negative transfer. On the other hand, the relative ease of the production of the coda $/ \mathrm{m} /$ for Southern Min speakers is a result of positive transfer. 
Mandarin and Southern Min speakers; thus, /m/ was found to be the most difficult for both MG and SG to learn. Stated differently, although the three target nasals all exist in Southern Min, Southern Min speakers show relative difficulty rather than equal difficulty with them, i.e., $/ \mathrm{m} />/ \mathrm{y} />/ \mathrm{n} /$ ('>' means 'more difficult than'). This result cannot be fully explicated in terms of CAH, suggesting that the comparison of L1 and L2 cannot completely predict the area of difficulty and the relative degree of difficulty.

In short, the transfer approach only predicts part of the results of this study and cannot fully provide a feasible account for the interlanguage English of coda nasals made by Taiwanese EFL learners. To our surprise, this study shows that there exists a preference for [n] over [m] or [n] in both MG and SG. The striking preference for [n] has drawn my greatest attention, which will be delved into at length in the following section.

\subsection{Unmarkedness Effect}

In this section, my intent is to argue for a preference for unmarked coronal [n] in the interlanguage English coda nasals as a result of an unmarkedness effect.

As to segmental markedness, coronals have been proved less marked in many languages, such as English, Mandarin, and Southern Min, as compared to the other places of articulation (see, among many others, Avery \& Rice, 1989; Botma \& van der Torre, 2000; Cho, 1991; Chung, 2002; Hayes \& Steriade, 2004; Hsu, 2006; Hume, 1996; Jun, 1995; Kean, 1975, 1980; Kiparsky, 1985; Maddieson, 1984; McCarthy \& Taub, 1992; Paradis \& Prunet, 1991; Prince \& Smolensky, 1993; Wan, 2002; Wilson, 2001). For instance, Wan (2002) investigated the asymmetry of consonant errors in Mandarin slips; she concluded that coronals tended to be replaced by other sounds, and, thus, they were underspecified or "unmarked" for any Place feature in the phonological system. In Southern Min, Chung (2002) found that coronal $/ \mathrm{n} /$ assimilates to its following place of feature, but labial $/ \mathrm{m} /$ and dorsal / $\mathrm{y} /$ do not; for example, /sin pu/ 'daughter-in-law' surfaces as [sim-pu]. ${ }^{17}$ Therefore, in terms of the markedness, coronals are easier for FL/L2 learners to learn than non-coronals.

This study shows that there exists a tendency toward the substitution of $/ \mathrm{m} /$ or $/ \mathrm{y} /$ by unmarked coronal [n]. The Mandarin and Southern Min speakers mispronounced the coda nasals as coronal [n] at the highest rate, and bilabial [m] at the lowest, with dorsal [n] somewhere in the middle. This result is predicted by the markedness theory - unmarked elements are expected to be easier for FL/L2 learners to learn. According to previous studies on language learning from the markedness perspective, unmarked structures are easier to learn than marked ones and are rarely violated by input data; it is, therefore, hard to prohibit the unmarked structures from surfacing in FL/L2 learners' interlanguage grammar (e.g., Broselow \& Xu, 2004; Broselow et al., 1998; Mazurkewich, 1984, 1985).

Coronals have proved unmarked in English, Mandarin, and Southern Min. This study displays that the coda nasals tend to be mispronounced as coronal [n], and among the three target coda nasals, $/ \mathrm{n} /$ is the most resistant to alternation, suggesting that the influence of the unmarkedness effect is present in the coda position with respect to the interlanguage English nasals. These findings are summarized in Table 14 where '>' means 'outnumbers.'

Table 14. The relative error rates among the target nasals (e.g., /m/ wrongly produced as [n])

\begin{tabular}{lll}
\hline $\begin{array}{c}\text { Language } \\
\text { Groups }\end{array}$ & Error Rates of Mispronounced Input Nasals & Error Rates of Wrong Output Nasals \\
\hline Mandarin & $/ \mathrm{m} /: 45.0 \%>/ \mathrm{y} /: 25.6 \%>/ \mathbf{n} /: 19.7 \%$ & {$[\mathbf{n}]: 27.4 \%>[\mathrm{y}]: 15.4 \%>[\mathrm{m}]: 2.3 \%$} \\
\hline Southern Min & $/ \mathrm{m} /: 30.5 \%>/ \mathrm{y} /: 26.4 \%>/ \mathbf{n} /: 19.3 \%$ & {$[\mathbf{n}]: 21.4 \%>[\mathrm{y}]: 13.9 \%>[\mathrm{m}]: 2.8 \%$} \\
\hline
\end{tabular}

Why does the unmarkedness emerge in the coda position? The data in Table 14 show a strong preference for unmarked [n] in the coda position in the sense that nasals tend to be neutralized toward coronal [n] in the syllable-final position in the interlanguage English; to put it another way, the preference for [n] is induced by the Place neutralization possibly. Based on the neutralization diagnostic, "unmarked" segments tend to be the normal result of neutralization. In Taiwanese EFL learners' English production of coda nasals, [n] is a more common output as compared to $[\mathrm{m}]$ or $[\mathrm{n}]$; therefore, the tendency toward $[\mathrm{n}]$ is possible to be a result of neutralization.

A coda is a position where outputs of neutralization commonly occur. Positional neutralization means that

\footnotetext{
${ }^{17}$ Based on the assimilation diagnostic, unmarked places of articulation will assimilate to marked ones, but marked ones will trigger assimilation.
} 
sounds are not in contrast in a particular position (e.g., syllable codas), and "unmarked" units are preferred to come out in this position (Kager, 2001). Kager (2001:407) remarks that "codas display a more restricted set of contrasts than onsets do," which is termed "coda neutralization." ${ }^{18}$ For example, Wu, a dialect of Chinese, neutralizes diminutives toward [n] in the course of the diachronic development of diminutive forms (Fang, 1986). This positional neutralization can give us an insight into the emergence of the unmarked in the coda position in the interlanguage English.

This section has shown that the results obtained in this study (i.e., the tendency toward unmarked [n]) cannot be fully explained by the transfer account alone. Instead, the tendency toward the unmarked coronal [n] reveals that the unmarkedness effect is at work in the production of English coda nasals by Taiwanese EFL learners.

\subsection{Relationships between Transfer and Unmarkedness}

This study shows that Southern Min speakers do have less difficulty with English coda [m] than Mandarin speakers do because coda $/ \mathrm{m} /$ is available in Southern Min but not in Mandarin. This finding can be explained as the influence of L1 sound system over L2 learning, according to the transfer theory.

However, among the three target nasals $[\mathrm{m}],[\mathrm{n}]$, and $[\mathrm{y}]$, coronal $[\mathrm{n}]$ is the easiest to learn and $[\mathrm{m}]$ the most difficult, with $[\mathrm{y}]$ in the middle, regardless of Taiwanese EFL learners' L1 background. The coronal nasals are unmarked relative to the other two nasals. It is the unmarkedness effect that shapes the interlanguage English coda nasals, according to the markedness theory.

Taken together, we can recognize that the transfer and unmarkedness effects interact to shape Taiwanese EFL learners' English production with respect to coda nasals. However, by which mechanism are the transfer and unmarkedness effects built into the learning process of English coda nasals? The output-oriented model, Optimality Theory, will provide us with an insightful explanation of how the transfer and markedness effects interact.

\section{Optimality Theoretical Framework}

\subsection{Constraints and Rankings Employed in This Study}

In this section, I attempt to explore how the transfer and unmarkedness effects work together in Taiwanese EFL learners' English production within the OT framework. Through the OT model, it is expected to transparently see the interplay of the transfer and unmarkedness effects in the interlanguage.

Let us convert the factors recognized in this study into OT constraints so as to discuss how Taiwanese EFL learners' L1 and the unmarkedness effect influence interlanguage English coda nasals within the OT framework. All of the constraints used in this study are summarized in Table 15:

Table 15. Phonological constraints and their rankings for Taiwanese EFL learners' English production

\begin{tabular}{lll}
\hline Family & $\begin{array}{l}\text { Constraints advanced } \\
\text { in previous studies }\end{array}$ & $\begin{array}{l}\text { Constraints used } \\
\text { in this study }\end{array}$ \\
\hline Faithfulness & IO-IDENT $_{\mathrm{FEAT}}($ e.g., Kager, 2001) & IO-IDENT \\
\hline \multirow{3}{*}{ MarkedT }
\end{tabular}

The validity of these constraints in Table 15 has been well documented in a good many studies (e.g., Goldsmith, 1990; Kager, 2001; Lombardi, 2001; Prince \& Smolensky, 1993; Roca \& Johnson, 1999; Zoll, 2004). These constraints are responsible for the Taiwanese EFL learners' English interlanguage grammar, and they are defined as follows:

(4) Markedness Constraints

*LAB-N-CODA: Any labial nasal is prohibited in the coda position.

*COR-N-CODA: Any coronal nasal is prohibited in the coda position.

${ }^{18}$ One of the reasons for why featural contrasts are suppressed in the coda is that codas are not in perceptually prominent positions, and featural distinctions are best realized in perceptually salient positions (Kager, 2001:408). 
*DOR-N-CODA: Any dorsal nasal is prohibited in the coda position.

(5) Faithfulness constraint

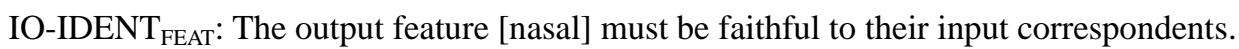

The rankings of these constraints for the L1 and interlanguage English are summarized as follows:

(6) Constraint rankings:

a. L1 grammar:

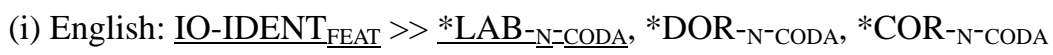

(e.g., $\left[\mathrm{k}^{\mathrm{h}} \mathrm{Im}\right],\left[\mathrm{k}^{\mathrm{h}} \mathrm{I \eta}\right],\left[\mathrm{k}^{\mathrm{h}} \mathrm{In}\right]$ )

(ii) Southern Min: $\underline{\text { IO-IDENT }} \underline{\mathrm{FEAT}} \gg{ }^{* \mathrm{LAB}-}{ }^{-}-\underline{\mathrm{CODA}},{ }^{* \mathrm{DOR}}{ }_{{ }_{\mathrm{N}}{ }^{-} \mathrm{CODA}},{ }^{*} \mathrm{COR}{ }_{-}{ }^{-}{ }_{\mathrm{CODA}}$

(e.g., $\left[\mathrm{k}^{\mathrm{h}} \mathrm{Im}\right],\left[\mathrm{k}^{\mathrm{h}} \mathrm{I \eta}\right],\left[\mathrm{k}^{\mathrm{h}} \mathrm{In}\right]$ )

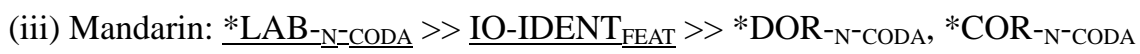

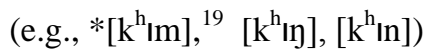

b. Interlanguage grammar (transfer effect):

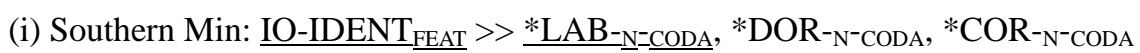

(e.g., $\left[\mathrm{k}^{\mathrm{h}} \mathrm{Im}\right],\left[\mathrm{k}^{\mathrm{h}} \mathrm{I \eta}\right],\left[\mathrm{k}^{\mathrm{h}} \mathrm{In}\right]$ )

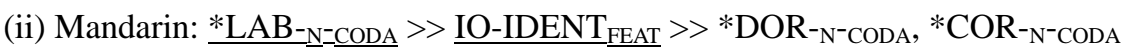

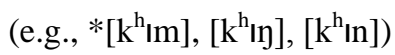

c. Interlanguage grammar (unmarkedness effect):

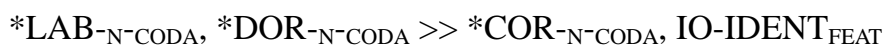

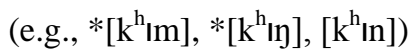

These constraints in $(6 \mathrm{a}, \mathrm{b})$ and (6c) are ranked according to L1 grammar (i.e., English, Southern Min, or Mandarin) and Place markedness subhierarchy, respectively (see Lombardi, 2001; Prince \& Smolensky, 1993; Zoll, 2004; also see Section 2.1.2 for detailed description of Place markedness subhierarchy).

With the basic notion of OT and constraints involved in this study, let us turn to how OT explains the findings observed in this study: both Taiwanese EFL learners' L1 and the unmarkedness effect influence the numbers of errors in English coda nasals simultaneously.

\subsection{English Constraint Ranking}

English, as mentioned previously, is a language with three-nasal-coda system. That is, English permits the three nasals, $/ \mathrm{m} /, / \mathrm{n} /$ and $/ \mathrm{y} /$, in the syllable-final position; therefore, constraints on nasal codas must be present. These constraints are $* \mathrm{LAB}-\mathrm{N}^{-} \mathrm{CODA}, * \mathrm{COR}-\mathrm{N}^{-} \mathrm{CODA}$, and $* \mathrm{DOR}-\mathrm{N}_{-\mathrm{CODA}}$. The competing constraint would be

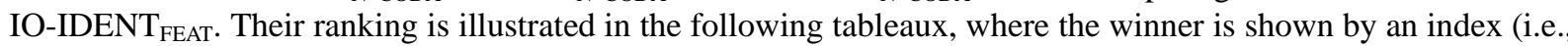
the pointing finger). A fatal violation is indicated by an exclamation mark '!' and the shading of cells means their violation content is no longer relevant. $* \mathrm{LAB}-{ }_{\mathrm{N}}{ }^{-} \mathrm{CODA}, * \mathrm{COR}-{ }_{\mathrm{N}}{ }^{-} \mathrm{CODA}$, and $* \mathrm{DOR}-\mathrm{N}^{-} \mathrm{CODA}$ are in mutual ranking, as there is no evidence for their ranking.

Table 16. English native form /pım/

\begin{tabular}{|c|c|c|c|c|}
\hline$/ \mathrm{pIm} /$ & IO-IDENT TEAT & *LAB- ${ }^{-}{ }^{-C O D A}$ & *DOR-N-CODA & *COR-N-CODA \\
\hline$\rightarrow$ a. $\left[\mathrm{p}^{\mathrm{h}} \mathrm{Im}\right]$ & & $*$ & & \\
\hline b. $\left[\mathrm{p}^{\mathrm{h}} \mathrm{In}\right]$ & $* !$ & & & $*$ \\
\hline c. $\left[\mathrm{p}^{\mathrm{h}} \mathrm{I \eta}\right]$ & $* !$ & & $*$ & \\
\hline
\end{tabular}

19 The star sign means the phonetic representation which is disallowed. 
Table 17. English native form /pın/

\begin{tabular}{|c|c|c|c|c|}
\hline$/ \mathrm{pIn} /$ & IO-IDENT $_{\text {FEAT }}$ & $* \mathbf{L A B}-\mathrm{N}^{*} \mathrm{CODA}$ & $*$ DOR-N-CODA & $*_{\text {COR}}{ }_{-\mathrm{N}-\mathrm{CODA}}$ \\
\hline a. $\left[\mathrm{p}^{\mathrm{h}} \mathrm{In}\right]$ & & & & * \\
\hline b. $\left[\mathrm{p}^{\mathrm{h}} \mathrm{Im}\right]$ & $* !$ & * & & \\
\hline c. $\left[\mathrm{p}^{\mathrm{h}} \mathrm{In}\right]$ & $* !$ & & $*$ & \\
\hline
\end{tabular}

Table 18. English native form /pı/

\begin{tabular}{|l|l|l|l|l|}
\hline$/ \mathrm{pIg} /$ & IO-IDENT $_{\text {FEAT }}$ & *LAB-N-CODA & $*$ DOR-N-CODA & $*$ COR-N-CODA \\
\hline a. $\left[\mathrm{p}^{\mathrm{h}} \mathrm{In}\right]$ & & & & \\
\hline b. $\left[\mathrm{p}^{\mathrm{h}} \mathrm{In}\right]$ & $* !$ & & & \\
\hline c. $\left[\mathrm{p}^{\mathrm{h}} \mathrm{Im}\right]$ & $* !$ & $*$ & & \\
\hline
\end{tabular}

The data in these tableaux show that Form a is the winner, since it qualifies as the most faithful candidate. That is, it follows the higher-ranked faithfulness constraint at the expense of violating lower-ranked markedness constraints, thereby violating minimally. A similar mechanism can be used to explain Southern Min native forms. However, this ranking in question cannot be applied to Mandarin grammar because unlike English and Southern Min, Mandarin does not allow bilabial nasals in the coda position, leading to the ranking of the constraint * LAB above *COR and *DOR.

\subsection{Southern Min Constraint Ranking}

Southern Min allows $/ \mathrm{m} /, / \mathrm{n} /$ and $/ \mathrm{y} /$ in the syllable-final position, as English does. The constraints on nasal codas involved in Southern Min are ${ }^{*} \mathrm{LAB}-\mathrm{N}^{-} \mathrm{CODA},{ }^{*} \mathrm{COR}-\mathrm{N}^{-} \mathrm{CODA}$, and ${ }^{*} \mathrm{DOR}-\mathrm{N}^{-} \mathrm{CODA}$. The competing constraint

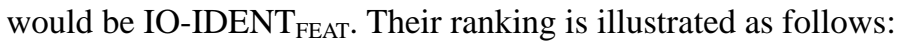

Table 19. Southern Min native form /pım/

\begin{tabular}{|l|l|l|l|l|}
\hline pIm/ & IO-IDENT $_{\text {FEAT }}$ & $*$ LAB-N-CODA & $*$ DOR-N-CODA & *COR-N-CODA \\
\hline a. $\left[\mathrm{p}^{\mathrm{h}} \mathrm{Im}\right]$ & & $*$ & & \\
\hline b. $\left[\mathrm{p}^{\mathrm{h}} \mathrm{In}\right]$ & $* !$ & & & $*$ \\
\hline c. $\left[\mathrm{p}^{\mathrm{h}} \mathrm{Im}\right]$ & $* !$ & & $*$ & \\
\hline
\end{tabular}

Table 20. Southern Min native form $/ \mathrm{p}$ !n/

\begin{tabular}{|l|l|l|l|l|}
\hline$/ \mathrm{pIn} /$ & IO-IDENT $_{\text {FEAT }}$ & $*$ LAB-N-CODA & $*$ DOR-N-CODA & *COR-N-CODA \\
\hline a. $\left[\mathrm{p}^{\mathrm{h}} \mathrm{In}\right]$ & & & & $*$ \\
\hline b. $\left[\mathrm{p}^{\mathrm{h}} \mathrm{Im}\right]$ & $* !$ & $*$ & & \\
\hline c. $\left[\mathrm{p}^{\mathrm{h}} \mathrm{Im}\right]$ & $* !$ & & $*$ & \\
\hline
\end{tabular}

Table 21. Southern Min native form $/ \mathrm{pln} /$

\begin{tabular}{|l|l|l|l|l|}
\hline pIn/ & IO-IDENT $_{\text {FEAT }}$ & $*$ LAB-N-CODA & $*$ DOR-N-CODA & $*$ COR-N-CODA \\
\hline a. $\left[\mathrm{p}^{\mathrm{h}} \mathrm{In}\right]$ & & & & \\
\hline b. $\left[\mathrm{p}^{\mathrm{h}} \mathrm{In}\right]$ & $* !$ & & & \\
\hline c. $\left[\mathrm{p}^{\mathrm{h}} \mathrm{Im}\right]$ & $* !$ & $*$ & & \\
\hline
\end{tabular}

The result, as we can see in Table 19 through Table 21, is that Candidate a is the optimal form, since it respects

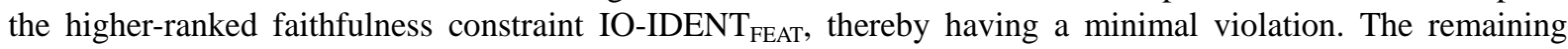
suboptimal candidates are ruled out because they violate the higher-ranked constraints, incurring a fatal violation.

\subsection{Mandarin Constraint Ranking}

Mandarin, as was previously mentioned, allows only $/ \mathrm{n} /$ and $/ \mathrm{n} /$ in the coda; constraints on nasal codas must therefore be present. These constraints involved in the coda are *LAB- ${ }_{-}^{-}{ }^{-C O D A}, * C O R-{ }_{-}^{-}{ }^{-C O D A}$, and $* D O R-{ }_{-}{ }^{-}$CODA, whose relative ranking is ${ }^{*} \mathrm{LAB}-{ }_{\mathrm{N}^{-} \mathrm{CODA}}>{ }^{*} \mathrm{COR}-{ }_{\mathrm{N}^{-} \mathrm{CODA}},{ }^{*} \mathrm{DOR}-{ }_{\mathrm{N}^{-}}{ }^{-C O D A}$. This ranking states that coronal $[\mathrm{n}]$ or dorsal $[\mathrm{g}]$ is possible to surface in the coda, and labial [m] is strictly prohibited from occurring in surface forms.

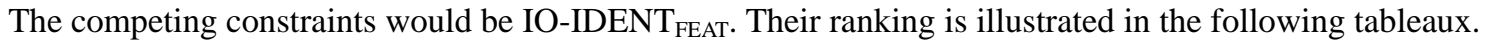


Table 22. Mandarin native form /pın/

\begin{tabular}{|c|c|c|c|c|}
\hline$/ \mathrm{pIn} /$ & *LAB-N-CODA & IO-IDENT FEAT $_{\text {IOT }}$ & *DOR-N-CODA & *COR-N-CODA \\
\hline a. $\left[\mathrm{p}^{\mathrm{h}} \mathrm{In}\right]$ & & & & * \\
\hline b. $\left[\mathrm{p}^{\mathrm{h}} \mathrm{I \eta}\right]$ & & $* !$ & * & \\
\hline c. $\left[\mathrm{p}^{\mathrm{h}} \mathrm{Im}\right]$ & $* !$ & $*$ & & \\
\hline
\end{tabular}

Table 23. Mandarin native form /pIn/

\begin{tabular}{|c|c|c|c|c|}
\hline$/ \mathrm{pIn} /$ & ${ }^{*} \mathbf{L A B}-\mathrm{N}^{*} \mathrm{CODA}$ & IO-IDENT FEAT $_{\text {T }}$ & *DOR-N*CODA & *COR-N-CODA \\
\hline a. $\left[\mathrm{p}^{\mathrm{h}} \mathrm{I \eta}\right]$ & & & $*$ & \\
\hline b. $\left[\mathrm{p}^{\mathrm{h}} \mathrm{In}\right]$ & & $* !$ & & $*$ \\
\hline c. $\left[\mathrm{p}^{\mathrm{h}} \mathrm{Im}\right]$ & $* !$ & $*$ & & \\
\hline
\end{tabular}

Table 24. /pIm/ banned in Mandarin

\begin{tabular}{|c|c|c|c|c|}
\hline$/ \mathrm{pIm} /$ & *LAB-N"CODA & IO-IDENT FEAT $_{\text {FT }}$ & *DOR-N-CODA & *COR-N-CODA \\
\hline a. $\left[\mathrm{p}^{\mathrm{h}} \mathrm{In}\right]$ & & * & & $*$ \\
\hline b. $\left[\mathrm{p}^{\mathrm{h}} \mathrm{In}\right]$ & & * & * & \\
\hline c. $\left[\mathrm{p}^{\mathrm{h}} \mathrm{Im}\right]$ & $* !$ & & & \\
\hline
\end{tabular}

Tableaux 22 and 24 show that Candidate (a) is the optimal form with no labial coda nasal because it obeys the higher-ranked constraint $* \mathrm{LAB}_{-} \mathrm{N}^{-} \mathrm{CODA}$, thereby having a minimal violation. The remaining suboptimal candidates are excluded, since they violate the higher-ranked constraints, incurring a fatal violation.

In Table 24, we can see that the forms $\left[\mathrm{p}^{\mathrm{h}} \mathrm{In}\right]$ and $\left[\mathrm{p}^{\mathrm{h}} \mathrm{I \eta}\right]$ are allowed in Mandarin, as they obey the highest-ranked constraint $* \mathrm{LAB}-\mathrm{N}^{-} \mathrm{CODA}$ at the expense of violating lower-ranked constraints. However, the form [ $\left.\mathrm{p}^{\mathrm{h}} \mathrm{Im}\right]$ is excluded and banned from surfacing in Mandarin, since it violates the highest-ranked constraint ${ }^{*}$ LAB- ${ }^{-}$CODA .

The three markedness constraints, $* \mathrm{LAB}, * \mathrm{COR}$, and $* \mathrm{DOR}$, are assumed to be present in every language grammar including Mandarin and Southern Min grammars. The contrast in codas between Mandarin and Southern Min is the rankings of the coda constraints. In Mandarin, the ranking is $*$ LAB- ${ }^{-}$CODA $>{ }^{*} \mathrm{COR}_{-\mathrm{N}^{-} \mathrm{CODA}}$, ${ }^{* D O R}{ }_{-}{ }^{-}$CODA, whereas in Southern Min, the three constraints are in mutual ranking.

\subsection{Interlanguage English Constraint Ranking}

This section will formulate and analyze the constraint ranking for the interlanguage English ranking with regard to the coda nasals.

A basic assumption of OT for L2 learning is that OT grammars are learnable with a set of constraints and their rankings and the constraint rankings would be reshuffled at each learning step; that is, a single error may drive an OT learner's to rearrange his/her current constraint ranking, which produces a wrong L2 output, by demoting all the violated constraints (Bunta \& Major, 2004; Tesar \& Smolensky, 2000; Kager et al., 2004). The purpose of reranking constraints is to reach target forms. This reranking of constraints occurring during the L2 learning implies that the constraint rankings for target outputs are not fixed but fluctuant in an L2 learner's mind.

\subsubsection{Transfer Effect}

This section will use the OT model to examine how the transfer effect works in interlanguage English phonology. In terms of OT, the transfer effect is interpreted as the transfer of the L1 rankings into L2.

Southern Min is as restrictive as English in terms of available nasals in the syllable coda position, while Mandarin is more restrictive than English. Both Southern Min and English permit the three final nasals, /m/, /n/, and $/ \mathrm{y} /$, but Mandarin allows only $/ \mathrm{n} /$ and $/ \mathrm{y} /$. Southern Min and English tend to remain faithful to their inputs,

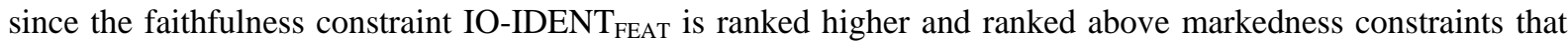
limit coda nasals. Conversely, in Mandarin grammar, the markedness constraint $* \mathrm{LAB}-\mathrm{N}^{-} \mathrm{CODA}$ is ranked higher

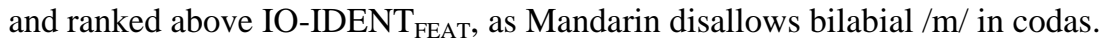

From preceding sections, we have recognized a transfer of Mandarin or Southern Min sound system into the interlanguage English with respect to the bilabial $/ \mathrm{m} /$ in codas. For Mandarin speakers, it is a case of the negative transfer; for Southern Min speakers, it is a positive transfer. This interlanguage English of native speakers of Mandarin deviates from the target language. To be specific, in Mandarin EFL learners' interlanguage English, the markedness constraint ${ }^{*} \mathrm{LAB}{ }_{-\mathrm{N}^{-} \mathrm{CODA}}$, which is ranked low in the target language 'English', is ranked high 
and fatally violated. Thus, Mandarin EFL learners' English with the high ranking *LAB- ${ }^{-}{ }^{-C O D A}$ motivates the prohibition of coda [m] from surfacing in the interlanguage English phonology.

As an example, let us take the English word 'comb' $\left[\mathrm{k}^{\mathrm{h}} \mathrm{om}\right]$. This study shows that Mandarin subjects wrongly produced $/ \mathrm{kom} /$ 'comb' as either [ $\left.\mathrm{k}^{\mathrm{h}} \mathrm{on}\right]$ or $\left[\mathrm{k}^{\mathrm{h}} \mathrm{on}\right]$ due to the transfer of Mandarin phonemic system to interlanguage English. Table 25 illustrates the interlanguage ranking, which is identical to that of Mandarin.

Table 25. Mandarin: Interlanguage forms [ $\left.\mathrm{k}^{\mathrm{h}} \mathrm{on}\right]$ or $\left[\mathrm{k}^{\mathrm{h}} \mathrm{o}\right]$ for $/ \mathrm{kom} /{ }^{\prime} \mathrm{comb}$ '

\begin{tabular}{|c|c|c|c|c|}
\hline$/ \mathrm{kom} /$ & ${ }^{*} \mathbf{L A B}-\mathrm{N}^{-} \mathrm{CODA}$ & IO-IDENT FEAT & *DOR-N-CODA & CCOR-N-CODA \\
\hline$\rightarrow \quad$ a. $\left[\mathrm{k}^{\mathrm{h}} \mathrm{on}\right]$ & & * & & * \\
\hline b. $\left[\mathrm{k}^{\mathrm{h}}\right.$ on] & & * & * & \\
\hline c. $\left[\mathrm{k}^{\mathrm{h}} \mathrm{om}\right]$ & $* !$ & & & \\
\hline
\end{tabular}

The data in Table 25 indicate that the outputs $\left[\mathrm{k}^{\mathrm{h}} \mathrm{on}\right]$ and $\left[\mathrm{k}^{\mathrm{h}} \mathrm{o}\right]$ are the winner, and $\left[\mathrm{k}^{\mathrm{h}} \mathrm{om}\right]$ is the loser. Here, the focus is the competition between the target form $\mathrm{c}$ and the interlanguage forms a and $\mathrm{b}$. In English, ${ }^{*} \mathrm{LAB}{ }^{-}{ }^{-}{ }^{-C O D A}$ is ranked lower, whereas the high ranking of * $\mathrm{LAB}-\mathrm{N}^{-} \mathrm{CODA}$ in the interlanguage excludes the target optimal $\mathrm{c}$ and singles out the outputs $\left[\mathrm{k}^{\mathrm{h}}\right.$ on] and $\left[\mathrm{k}^{\mathrm{h}}\right.$ on]. The interlanguage grammar has assigned greater importance to the avoidance of bilabial $/ \mathrm{m} /$ in the coda position than to the avoidance of coronal $/ \mathrm{n} /$ or dorsal $/ \mathrm{y} /$. It is evident that phonological properties from Mandarin speakers' native language surface in their interlanguage; that is, the ranking of a set of universally violable constraints that limits nasal inventory in codas in Mandarin is found to be transferred into the interlanguage English phonology.

As mentioned above, Mandarin speakers mispronounced $/ \mathrm{kom} /$ 'comb' as either $\left[\mathrm{k}^{\mathrm{h}} \mathrm{on}\right]$ or $\left[\mathrm{k}^{\mathrm{h}} \mathrm{on}\right]$ in their interlanguage English. The choice of the optimal form between $\left[\mathrm{k}^{\mathrm{h}} \mathrm{on}\right]$ and $\left[\mathrm{k}^{\mathrm{h}} \mathrm{on}\right]$ comes to the determination of

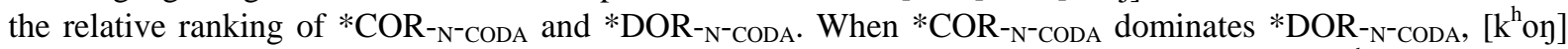
will be chosen as the optimal output in the interlanguage English; when this ranking is reverse, $\left[\mathrm{k}^{\mathrm{h}}\right.$ on] will be the optimal candidate. This suggests that the constraint rankings are unstable in the interlanguage when FL/L2 learners develop their interlanguage grammar, as argued in Tesar and Smolensky (2000). Interestingly, the results of this study reveal that the unmarked output [n] is more likely to occur in the interlanguage English for both Mandarin and Southern Min speakers, as compared to [n], suggesting the emergence of the unmarked in the interlanguage English. This will be discussed in the subsequent section.

\subsubsection{Unmarkedness Effect}

Within the OT framework, this section will examine how the unmarkedness effect works in interlanguage English, leading to a preference for unmarked coronal nasals.

In OT, the unmarkedness effect becomes visible through the ranking of constraints, that is, through the presence of the effect of lower-ranked markedness constraints. As to how the Place markedness hierarchy is formally expressed in the OT model, I follow Hume and Tserdanelis (2002) and Prince's (1997a, b, 1999) ideas of markedness hierarchies. They argue that constraints related to markedness hierarchies must be freely rankable (but not universally fixed, as argued by Prince and Smolensky (1993) and Lombardi (2001)) and be in contiguous ranges, beginning with the most marked structure. The argument for the free rankability of markedness hierarchies are based on the fact that there is no single feature within a phonological class which can be absolutely defined as unmarked within a particular language or across languages. In terms of place features, many studies have proved that any of the labial, coronal, and velar is possible to function as phonologically unmarked (Cho, 1991, for coronal in Korean; Fonte, 1996, for labials in Kiribatese and Kilivila; Hume \& Tserdanelis, 2002, for labials in Sri Lankan Portuguese Creole; Mills, 1975, for velars in Buginese, to name just a few).

Drawing the previous arguments together, I propose that it is the Place markedness hierarchy, *LAB, *DORS >> *COR, which emerges in Taiwanese EFL learners' interlanguage English, since coronals are less marked in English, Mandarin, and Southern Min. This ranking prefers less marked coronal [n] to more marked bilabial [m]

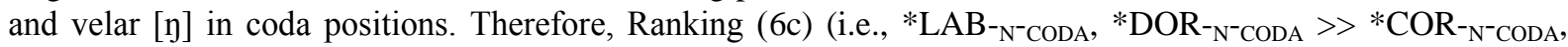
IO-IDENT $_{\mathrm{FEAT}}$ ) reflects the occurrence of the unmarkedness effect in Taiwanese EFL learners' English of coda nasals.

Now let us see how the markedness hierarchy operates in interlanguage forms. The outputs [ $\left.\mathrm{k}^{\mathrm{h}} \mathrm{In}\right] \mathrm{for} / \mathrm{kln} /$ ' $\mathrm{kin}$ ', [ $\mathrm{k}^{\mathrm{h}} \mathrm{on}$ ] for / kom/ 'comb', and [ban] for /ban/ 'bong' are provided as examples, and they are shown in Table 26 through Table 28 in turn. 
Table 26. Mandarin \& Southern Min: Interlanguage form [ $\left.\mathrm{k}^{\mathrm{h}} \mathrm{on}\right]$ for $/ \mathrm{kon} /$ ' $\mathrm{kin}$ '

\begin{tabular}{|r|l|l|l|l|}
\hline$/$ kon/ & $*$ LAB-N-CODA & *DOR-N-CODA & *COR-N-CODA & IO-IDENT \\
\hline aEAT \\
\hline b. $\left[\mathrm{k}^{\mathrm{h}} \mathrm{on}\right]$ & & & $*$ & \\
\hline b. $\left[\mathrm{k}^{\mathrm{h}} \mathrm{on}\right]$ & & $* !$ & & $*$ \\
\hline c. $\left[\mathrm{k}^{\mathrm{h}} \mathrm{om}\right]$ & $* !$ & & & $*$ \\
\hline
\end{tabular}

The ranking in Table 26 selects the optimal output $\left[\mathrm{k}^{\mathrm{h}} \mathrm{In}\right]$, which obeys the higher-ranked constraints at the expense of violating the lower-ranked constraints. The remaining outputs are excluded, as they fatally violate the higher-ranked constraints.

Table 27. Mandarin \& Southern Min: Interlanguage form [ $\left.\mathrm{k}^{\mathrm{h}} \mathrm{on}\right]$ for $/ \mathrm{kom} /{ }^{\text {'comb' }}$

\begin{tabular}{|c|l|l|l|l|}
\hline$/$ kom/ & *AAB- ${ }^{-}$CODA & DOR- ${ }^{-}$CODA & $*$ COR-N-cODA & IO-IDENT \\
\hline a. $\left[\mathrm{k}^{\mathrm{h}} \mathrm{on}\right]$ & & & $*$ & $*$ \\
\hline b. $\left[\mathrm{k}^{\mathrm{h}} \mathrm{o \eta}\right]$ & & $* !$ & & $*$ \\
\hline c. $\left[\mathrm{k}^{\mathrm{h}} \mathrm{om}\right]$ & $* !$ & & & \\
\hline
\end{tabular}

The constraint ranking in Table 27 indicates that the output $\left[\mathrm{k}^{\mathrm{h}}\right.$ on] is the winner, and the remaining suboptimal forms are the losers. This ranking reveals that the influence of the unmarkedness effect is present, since the effect of the inactive lower-ranked markedness constraints becomes activated and that of the faithfulness constraint (i.e., IO-IDENT $_{\text {FEAT }}$ ) becomes invisible. This leads to the fact that the interlanguage grammar has assigned greater importance to the avoidance of more marked [m] and [n] in the coda position than to the avoidance of less marked [n].

Table 28. Mandarin \& Southern Min: Interlanguage form [ban] for /bay/ 'bong'

\begin{tabular}{|c|l|l|l|l|}
\hline /bay/ & *LAB-N-CODA & *DOR-N-CODA & $*$ COR-N-CODA & IO-IDENT \\
\hline a. $[\mathrm{ban}]$ & & & $*$ & $*$ \\
\hline b. $[\mathrm{ban}]$ & & $* !$ & & \\
\hline c. $[\mathrm{bam}]$ & $* !$ & & & $*$ \\
\hline
\end{tabular}

The ranking in Table 28 singles out the optimal output [ban] and excludes the other suboptimal candidates, which fatally violate the higher-ranked markedness constraints. The lower-ranked markedness constraints, the effect of which becomes visible, are the source of the emergence of the unmarked coda nasals in the interlanguage form. Therefore, under this ranking, the unmarked [n] in the coda emerges in the interlanguage form.

From the data in Table 26 through Table 28, we can see that the unmarkedness effect exerts its influence on the

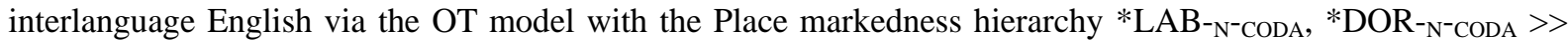
${ }^{*} \mathrm{COR}-\mathrm{N}^{-}$CODA. In this ranking, the influence of the lower-ranked markedness constraints is present, leading the unmarkedness effect to become visible in interlanguage English of coda nasals.

\subsubsection{Interaction of Transfer and Markedness in OT}

From the previous sections, we can see how OT accounts for transfer and markedness nicely. Also, this constraint-based model allows us to unify markedness and transfer accounts.

To begin with, let us take $\left[\mathrm{k}^{\mathrm{h}} \mathrm{Im}\right]$ or $\left[\mathrm{k}^{\mathrm{h}} \mathrm{In}\right]$ for $/ \mathrm{k} \mathrm{Im} /$ ' $\mathrm{kim}$ ' made by Southern Min speakers as an example. Consider the following two tableaux.

Table 29. Southern Min: Transfer Effect on Interlanguage form [kım] for $/ \mathrm{kIm} /$ ' kim'

\begin{tabular}{|c|c|c|c|c|}
\hline /kım/ & IO-IDENT $_{\text {FEAT }}$ & *LAB-N-CODA & *DOR-N-CODA & *COR-N-CODA \\
\hline a. $\left[\mathrm{k}^{\mathrm{h}} \mathrm{Im}\right]$ & & $*$ & & \\
\hline b. $\left[\mathrm{k}^{\mathrm{h}} \mathrm{In}\right]$ & $* !$ & & & $*$ \\
\hline c. $\left[\mathrm{k}^{\mathrm{h}} \mathrm{I} \mathrm{\eta}\right]$ & $* !$ & & $*$ & \\
\hline
\end{tabular}


Table 30. Southern Min: Unmarkedness Effect on Interlanguage form [ $\left.\mathrm{k}^{\mathrm{h}} \mathrm{In}\right]$ for $/ \mathrm{k} \mathrm{km} /$ ' $\mathrm{kim}$ '

\begin{tabular}{|l|l|l|l|l|}
\hline$/ \mathrm{k} I \mathrm{~m} /$ & ${ }^{\prime} \mathbf{L A B}-\mathrm{N}^{-C O D A}$ & *DOR-N-CODA & *COR-N-CODA & IO-IDENT \\
\hline aEAT \\
\hline b. $\left[\mathrm{k}^{\mathrm{h}} \mathrm{In}\right]$ & & & $*$ & $*$ \\
\hline c. $\left[\mathrm{k}^{\mathrm{h}} \mathrm{I} \mathrm{l}\right]$ & & $* !$ & & \\
\hline
\end{tabular}

In Table 29, we can see that the constraint ranking for Southern Min grammar is transferred to the interlanguage English with respect to coda nasals, leading to the presence of coda bilabial [m]. However, Table 30 shows that only unmarked coronal nasals are allowed to surface in the interlanguage English produced by Southern Min speakers, since the influence of the lower-ranked markedness constraints is present.

Let us look at another example made by Mandarin speakers, as shown below.

Table 31. Mandarin: Transfer Effect on Interlanguage form [ $\left.\mathrm{p}^{\mathrm{h}} \mathrm{I}\right]$ for $/ \mathrm{p} ı \mathrm{y} /$ 'ping'

\begin{tabular}{|c|c|c|c|c|}
\hline$/ \mathrm{plg} /$ & *LAB-N"CODA & IO-IDENT $_{\text {FEAT }}$ & *DOR-N-CODA & *COR-N-CODA \\
\hline$\rightarrow \quad$ a. $\left[\mathrm{p}^{\mathrm{h}} \mathrm{In}\right]$ & & & * & \\
\hline b. $\left[\mathrm{p}^{\mathrm{h}} \mathrm{In}\right]$ & & *! & & * \\
\hline c. $\left[\mathrm{p}^{\mathrm{h}} \mathrm{Im}\right]$ & $* !$ & * & & \\
\hline
\end{tabular}

Table 32. Mandarin: Unmarkedness Effect on Interlanguage form [pın] for /pıly 'ping'

\begin{tabular}{|l|l|l|l|l|}
\hline$/ \mathrm{p} ı \mathrm{y} /$ & *LAB-N-CODA & *DOR-N-CODA & *COR-N-CODA & IO-IDENT \\
\hline a. $\left[\mathrm{p}^{\mathrm{h}} \mathrm{In}\right]$ & & & $*$ & $*$ \\
\hline b. $\left[\mathrm{p}^{\mathrm{h}} \mathrm{I}\right]$ & & $* !$ & & \\
\hline c. $\left[\mathrm{p}^{\mathrm{h}} \mathrm{Im}\right]$ & $* !$ & & & $*$ \\
\hline
\end{tabular}

The data in Table 31, as we can see, show that the constraint ranking for Mandarin grammar is transferred to the interlanguage English. However, the data in Table 32 indicate that only unmarked coronal $[\mathrm{n}]$ is available in the interlanguage produced by Mandarin speakers because marked bilabial $[\mathrm{m}]$ and dorsal $[\mathrm{g}]$ are strictly prohibited from surfacing under the influence of the umarkedness effect.

From the four tableaux above, we can see that differences in the constraint rankings result in the variation of the interlanguage coda nasals, which is attributed to the transfer or markedness effects. That is, OT explains the interaction of transfer and markedness as the reranking of the constraints. ${ }^{20}$

However, why can OT unify the two different effects? OT allows us to unify the markedness and transfer accounts, since markedness has been built directly into the grammar in the form of markedness constraints and transfer is interpreted as the transfer of constraint rankings of L1 to L2. At the beginning of learning FL/L2 grammar, an OT learner will start with his/her L1 constraint rankings (Tesar \& Smolensky, 2000); the emergence of the unmarked is due to the demotion of all the violated constraints which result in the preservation of lexical contrasts or the occurrence of more marked structures (Grijzenhout \& Van Rooy, 2001). For example, in the cases of Mandarin and Southern Min speakers, the faithfulness constraint IO-IDENT FEAT $_{\text {is demoted and the }}$ markedness constraints are therefore ranked higher, leading to the emergence of the unmarked coronal [n] in the coda position. ${ }^{21}$

This study shows that OT can nicely account for the interaction between the transfer and unmarkedness effects in Taiwanese EFL learners' interlanguage English of coda nasals. OT captures the dynamic interaction among the L1, interlanguage, and L2 grammars in one step, by showing the hierarchical relations among different constraints. This reveals that OT can unify transfer and markedness directly.

\section{Conclusion}

The purpose of this study was to delve into how the transfer and unmarkedness effects interact to shape English

${ }^{20}$ However, regarding the gradation phenomenon (i.e., wrong inputs: $/ \mathrm{m} />/ \mathrm{y} />/ \mathrm{n} /$ and wrong outputs: $[\mathrm{n}]>[\mathrm{y}]>[\mathrm{m}]$ ), what would a grammar look like in cases like this and how can the gradient degree of preference be captured in OT? Considering the scope and the focus of this paper, a full-fledged analysis to account for these questions is not included.

${ }^{21}$ Salient positions (like onset) rather than weak positions (like coda) are particularly protected by faithfulness constraints and do not undergo any phonological processes like positional neutralization (Beckman, 2004; Zoll, 2004). 
coda nasals produced by Taiwanese EFL learners. In response to this issue, I conducted an English production experiment in which Mandarin and Southern Min native speakers participated.

In this study, there were three major findings. First, in terms of English bilabial nasals, Mandarin speakers had more difficulty with them than Southern Min speakers did, suggesting a negative transfer of L1 phonemic system to L2. Second, both the language groups tended to mispronounce English coda nasals as less marked [n] rather than more marked $[\mathrm{m}]$ or $[\mathrm{g}]$, suggesting the emergence of the unmarked. Based merely on the traditional CAH account, it was not clear why there existed a strong tendency toward unmarked $[\mathrm{n}]$ in the interlanguage phonology, since Southern Min can allow all of the three nasals, $/ \mathrm{m} /, / \mathrm{n} /$, and $/ \mathrm{y} /$ in the coda position. These two findings unveiled an interaction between the transfer and unmarkedness effects in the interlanguage English concerning coda nasals. Finally, the results of this study reveal that while the unmarkedness and transfer effects influence the learning of English coda nasals together, the unmarkedness effect overrides the transfer effect in shaping Taiwanese EFL learners' English interlanguage, thereby leading to a strong preference for unmarked [n] over $[\mathrm{m}]$ or $[\mathrm{y}]$ in phonetic representations.

Within the OT framework, we can see how OT succinctly and insightfully accounts for the transfer effect or the unmarkedness effect on interlanguage English with a set of constraints and their different rankings. For the transfer effect, we can see that the constraint ${ }^{*} \mathrm{LAB}-\mathrm{N}^{-}{ }^{-} \mathrm{CODA}$, which bans $/ \mathrm{m} /$ in codas in Mandarin, is found to be transferred high-ranked into Mandarin EFL learners' interlanguage English, leading to the interlanguage ranking

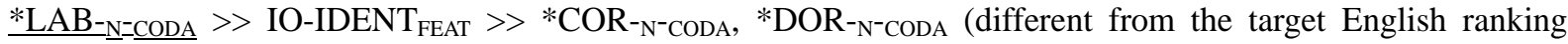

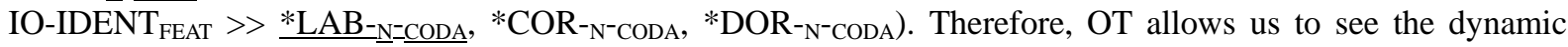
interaction among the L1, interlanguage, and L2 grammars in one step. For the emergence of the unmarked, OT assumes that the low-ranked markedness constraints are ranked above the faithfulness constraints and their influence becomes visible, thus leading to the emergence of unmarked outputs. For example, /som/ becoming [son] was due to the enforcement of the higher-ranked Place markedness hierarchy ${ }^{*} \mathrm{LAB}-\mathrm{N}^{-}{ }^{-C O D A}$, ${ }^{* D O R}{ }_{-}{ }^{-}$CODA $\gg *{ }^{*} \mathrm{COR}_{-}{ }^{-}{ }^{-C O D A}$ in the interlanguage English. Taken together, through a set of universally violable constraints and their different rankings, OT allows us to clearly see the correlation between the transfer and unmarkedness effects in the interlanguage English. ${ }^{22}$

\section{References}

Alderete, J. (2004). Dissimilation as local conjunction. In J.J. McCarthy (ed.), Optimality Theory in Phonology: a reader, 394-406. Oxford: Blackwell. (Available at Rutgers Optimality Archive, ROA). http://dx.doi.org/10.1002/9780470756171.ch20

Altenberg, E. P., \& R. M. Vago. (1987). Theoretical implications of an error analysis of second language phonology production. In G. Ioup and S. H. Weinberger (eds.), Interlanguage Phonology: the acquisition of a second language sound system, 148-164. Cambridge: Newbury House.

Aoyama, K. (2003). Perception of syllable-initial and syllable-final nasals in English by Korean and Japanese speakers. Second Language Research, 19(3), 251-265. http://dx.doi.org/10.1191/0267658303sr222oa

Avery, P., \& K. Rice. (1989). Segment structure and coronal underspecification. Phonology, 6, 179-200. http://dx.doi.org/10.1017/S0952675700001007

Bada, E. (2001). Native language influence on the production of English sounds by Japanese learners. The Reading Matrix, 1(2), 1-15.

Beckman, J. (2004). Positional faithfulness. In J. McCarthy (ed.), Optimality Theory in Phonology: a reader, 310-342. Oxford: Blackwell. http://dx.doi.org/10.1002/9780470756171.ch16

Botma, B., \& E. J. van der Torre. (2000). Markedness in the nasal component. Paper presented at the $8^{\text {th }}$ Manchester Phonology Meeting: Special session abstracts, University of Manchester. (Available at http://www.englang.ed.ac.uk/mfm/ 8mfmspeshseh.html)

\footnotetext{
${ }^{22}$ However, this paper does not tackle the issues related to the structure or mechanism of switching from one effect to another because they are beyond the scope of this paper. The first question is: what is the structure of the interlanguage that allows both transfer and unmarkedness effects to co-exit (i.e. two different constraint rankings in the grammar in their OT analysis)? Assuming that for the basic level learners who strongly rely on L1 grammar, the transfer effect forces the preservation of the constraint ranking of L1 in the interlanguage. Then, what triggers the unmarkedness effect, which is not active in the L1 grammar, to step in when producing L2 words? Could it be learning-stage determined? Or, is it the case that the interlanguage grammar is more vulnerable for universal tendency to emerge? If so, how is this presented in the grammar? These questions can be discussed in a separate paper.
} 
Briére, F. (1966). An investigation of phonological interference. Language, 42(4), 768-796. http://dx.doi.org/10.2307/411832

Broselow, E. S. I. Chen, and C. Wang. (1998). The emergence of the unmarked in second language phonology. Studies in Second Language Acquisition, 20, 261-280. http://dx.doi.org/10.1017/S0272263198002071

Broselow, E., \& Z. Xu. (2004). Differential difficulty in the acquisition of second language phonology. International Journal of English Studies, 4(2), 135-163.

Bunta, F., \& R. C. Major. (2004). An optimality theoretic account of Hungarian ESL learners acquisition of $/ \varepsilon /$ and /æ/. International Review of Applied Linguistics in Language Teaching (IRAL), 42, 277-298. http://dx.doi.org/10.1515/iral.2004.014

Chang, Y. P. (2002). The Study of Foreign Language Intonation: the Case of Taiwanese Learning English as a Second Language. Master's thesis, National Taiwan University, Taiwan.

Chiang, T. (1979). Some interference of English intonations with Chinese tones. International Review of Applied Linguistics in Language Teaching (IRAL), 17, 245-250.

Cho, Y. M. Y. (1991). On the Universality of the Coronal Articulator. In C. Paradis and J. F. Prunet (eds.), The Special Status of Coronals: Internal and External Evidence, 159-179. San Diego: Academic Press.

Chomsky, N. (1965). Aspects of the Theory of Syntax. Cambridge, MA: The MIT Press.

Chomsky, N. (1981). Markedness and core grammar. In A. Belletti, L. Brandi, and L. Rizzi (eds.), Theory of Markedness in Generative Grammar, 123-146. Pisa: Scuola Normale Superiore.

Chomsky, N., \& M. Halle. (1968). The Sound Pattern of English. New York: Harper and Row.

Chung, R.-F. (2002). Tai-Yu de Yu-Yin J-Chu (The Sound System of Southern Min). Taipei: Crane. (in Chinese)

Corder, S. (1967). The significance of learner's errors. International Review of Applied Linguistics, 5, 161-70. http://dx.doi.org/10.1515/iral.1967.5.1-4.161

Cortés, N. C. (2006). Negative language transfer when learning Spanish as a foreign language. Interlingüística, $16,1-11$.

de Lacy, P. (2004). Markedness and conflation in Optimality Theory. Phonology, 21, 145-199. http://dx.doi.org/10.1017/S0952675704000193

Denes, P.B. (1963). On the statistics of spoken English. Journal of the Acoustical Society of America, 35, 892-904. http://dx.doi.org/10.1121/1.1918622

Eckman, F. (1987). Markedness and the contrastive analysis hypothesis. In G. Ioup, \& S.H. Weinberger (eds.), Interlanguage Phonology: the acquisition of a second language sound system, 55-69. Cambridge, MA: Newbury House Publishers.

Fang, S. X. (1986). Zhejiang Yi-wu Fang-yan [n]-Hua-Yun (The Dialect of Zhejiang: the rhyme [n] in Yi-Wu). Chong-Gou Yu-Wen (Chinese Language), 6, 442-446. (in Chinese)

Felix, S. (1980). Interference, interlanguage, and related issues. In S. Felix (ed.), Second Language Development: Trends and Issues, 93-107. Tübingen: Gunter Narr Verlag.

Flege, J. E., \& C. Wang. (1989). Native language phonotactic constraints affect how well Chinese subjects perceive the word-final English /t/-/d/ contrast. Journal of Phonetic, 17, 299-315.

Fonte, I. (1996). Restrictions on Coda: An Pptimality Theoretic Account of Phonotactics. MA thesis, McGill University, Montreal.

Frisch, S., \& R. Wright. (2002). The phonetics of phonological speech errors: An acoustic analysis of slips of the tongue. Journal of Phonetics, 30, 139-162. http://dx.doi.org/10.1006/jpho.2002.0176

Goldsmith, J. (1990). Autosegmental and Metrical Phonology. Oxford: Blackwell.

Gradman, H. (1971). Limitations of contrastive analysis predictions. Working Papers in Linguistics, 3, 11-15.

Greenberg, J. (1974). Language Typology: A Historical and Analytic Overview. The Hague: Mouton. http://dx.doi.org/10.1515/9783110886436

Greenberg, J. H. (1980). Language Universals. The Hague: Mouton.

Greenberg, J. H. (1991). Typology/Universals and Second Language Acquisition. In T. Hubner (ed.), Crosscurrents, 37-42. Amsterdam: John Benjamin. 
Grijzenhout, J., \& B. Van Rooy. (2001). Second language phonology: Acquisition trough gradual constraint demotion. Theorie des Lexikons 119. Universität Düsseldorf.

Hayes, B., \& D. Steriade. (2004). Introduction: the phonetic bases of phonological markedness. In B.Hayes, R. Kirchner, and D. Steriade (eds.), Phonetically-based Phonology, 1-33. Cambridge: Cambridge University Press. http://dx.doi.org/10.1017/CBO9780511486401.001

Hsu, H. L. (2003). The Study of Intonation in English Interrogatives: Taiwanese Learning English as a Foreign Language. Master's thesis, National Taiwan University, Taiwan.

Hsu, H. L. (2006). Mandarin Nasal Place Variability_Assimilation or markedness- within an OT Framework. Paper presented at the $7^{\text {th }}$ High Desert Linguistics Society Conference (HDLS-7), University of New Mexico, U.S.A.

Hsu, H. L. (2011). The emergence of an Unmarkedness effect in Mandarin speech errors: Nasals in a coda position. Language and Speech, 54(3), 307-340. http://dx.doi.org/10.1177/0023830911402473

Hume, E. (1996). Coronal consonant, front vowels parallels in Maltese. Natural Language and Linguistic Theory (NLLT), 14, 163-203. http://dx.doi.org/10.1007/BF00133405

Hume, E., \& G. Tserdanelis. (2002). Labial unmarkedness in Sri Lankan Portuguese Creole. Phonology, 19, 441-458. http://dx.doi.org/10.1017/S0952675703004421

Inagaki, S. (1997). Japanese and Chinese learners' acquisition of the narrow-range rules for the dative alternation in English. Language Learning, 47, 637-669. http://dx.doi.org/10.1111/0023-8333.00024

Itô, J., \& A. Mester. (1994). Reflections on CodaCond and Alignment. In J. Merchant, J. Padgett, and R. Walker (eds.), Phonology at Santa Cruz, 27-46. Santa Cruz: Linguistics Research Center, University of California. (Available at Rutgers Optimality Archive, ROA)

Iverson, G., \& S. Lee. (1995). Variation as optimality in Korean cluster reduction. In J. Fuller, H. Han, and D. Parkinson (eds.), Proceedings of the Eleventh Eastern States Conference on Linguistics, 174-185. Ithaca, NY: DMLL Publications.

Jakobson, R. (1941). Kindersprache, Aphasie and Allgemeine Lautgesetze. (Child Language, Aphasia and Phonological Universals, A.R. Keiler, Trans. (1968). The Hague: Mouton.

Johansson, F. A. (1973). Immigrant Swedish Phonology: a study in multiple contact Analysis. Lund: WEK Gleerup.

Johnson, K. (1997). Acoustic and Auditiory Phonetics. Cambridge: Blackwell.

Jun, J. (1995). Place assimilation as the result of conflicting perceptual and articulatory constraints. Proceedings of the 14th West Coast Conference on Formal Linguistics (WCCFL 14), 221-237.

Kager. R. (2001). Optimality Theory. Cambridge: Cambridge University press.

Kager. R., J. Pater, \& W. Zonneveld. (2004). Constraints in Phonological Acquisition. Cambridge: Cambridge University Press. http://dx.doi.org/10.1017/CBO9780511486418

Kean, M. (1975). The Theory of Markedness in Generative Grammar. Ph.D. dissertation, MIT, Cambridge.

Kean, M. (1980). The Theory of Markedness in Generative Grammar. Bloomington: Indiana University Press.

Kenstowicz, M., \& C. Kisseberth. (1979). Generative phonology. San Diego: Academic.

Kiparsky, P. (1985). Some consequences of lexical phonology. Phonology Yearbook, 2, 85-138. http://dx.doi.org/10.1017/S0952675700000397

Koda, K. (1990). The use of L1 reading strategies in L2 reading: effects of L1 orthographic structures on L2 Phonological recording strategies. Studies in Second Language Acquisition, 12, 393-410. http://dx.doi.org/10.1017/S0272263100009499

Koutsoudas A., \& O. Koutsoudas. (1983). A contrastive analysis of the segmental phonemes of Greek and English. In B. W. Robinett and J. Schachter (eds.), Second Language Learning: Contrastive Analysis, Error Analysis, and Related Aspects, 41-62. Ann Arbor: University of Michigan Press.

Ladefoged, P. (2002). Vowels and Consonants: An Introduction to the Sounds of Languages. Malden: Blackwell.

Lado, R. (1957). Linguistics Across Cultures. Ann Arbor: University of Michigan Press.

Lai, U. W. (2000). Cantonese durational and pitch transfer tendencies in second language learning. Nihon 
Gakkan No., 4, 31-40, Hong Kong: Society of Japanese Language Education.

Lehn, W., \& W. R. Slager. (1983). A contrastive study of Egyptian Arabic and American English: the segmental phonemes. In B. W. Robinett and J. Schachter (eds.), Second Language Learning: Contrastive Analysis, Error Analysis, and Related Aspects, 32-40. Ann Arbor: University of Michigan Press.

Liao, F. (1998). Learning and teaching pronunciation. Jiangguo Bulletin, 17, 43-56.

Lin, Y. H. (2002). Interlanguage Variability: Studies on L2 Consonant Cluster Simplification Interlanguage Variability. Ph.D. dissertation, University of Tsing Hua, Hsinchu, Taiwan.

Lombardi, L. (2001). Segmental Phonology in Optimality Theory: Constraints and representations. Cambridge: Cambridge University Press.

Lombardi, L. (2002). Coronal epenthesis and markedness. Phonology, 19, $219-251$. http://dx.doi.org/10.1017/S0952675702004323

Lombardi, L. (2004). Positional Faithfulness and Voicing Assimilation in Optimality Theory. In J. J. McCarthy (ed.), Optimality Theory in Phonology: a reader, 343-364. Oxford: Blackwell. http://dx.doi.org/10.1002/9780470756171.ch17

Maddieson, I. (1984). Patterns of Sounds. Cambridge, England: Cambridge University Press. http://dx.doi.org/10.1017/CBO9780511753459

Major, R., \& M. Faudree. (1996). Markedness universals and the acquistion of voicing contrasts by Korean speakers of English. Studies in Second Language Acquisition, 18, 69-90. http://dx.doi.org/10.1017/S0272263100014686

Mazurkewich, I. (1984). The acquisition of the dative alternation by second language learners and linguistic theory. Language Learning, 34, 91-109. http://dx.doi.org/10.1111/j.1467-1770.1984.tb00997.x

Mazurkewich, I. (1985). Syntactic markedness and language acquisition. Studies in Second Language Acquisition, 7, 15-36. http://dx.doi.org/10.1017/S0272263100005131

McCarthy, J., \& A. Prince. (2004). The emergence of the unmarked. In J. McCarthy (ed.), Optimality Theory in Phonology: a reader, 483-494. Oxford: Blackwell. (Available on Rutgers Optimality Archive, ROA) http://dx.doi.org/10.1002/9780470756171.ch26

McCarthy, J., \& A. Taub. (1992). Review of the special status of coronals: internal and external evidence. Phonology, 9, 363-370. http://dx.doi.org/10.1017/S0952675700001664

Mills, R. F. (1975). Proto South Sulawesi and Proto Austronesian Phonology. Ph.D. dissertation, University of Michigan.

Monahan, P. (2001). Brazilian Portuguese coda condition constraint transfer into L2 English. UF Journal of Undergraduate Research, 3(4). http://www.clas.ufl.edu/jur/200112/papers/paper_monahan.html)

Montrul, S. (1997). Transitivity Alternations in Second Language Acquisition: A Crosslinguistic Study of English, Spanish, and Turkish. Ph.D. dissertation, McGill University, Montreal.

Moulton, W. (1962). The sounds of English and German. Chicago: The University of Chicago Press.

Palmberg, R. (1987). Patterns of vocabulary development in foreign-language learners. Studies in Second Language Acquisition, 9, 201-219. http://dx.doi.org/10.1017/S0272263100000474

Paradis, C., \& J. F. Prunet. (1991). Introduction: Asymmetry and visibility in consonant articulations. In C. Paradis and J. F. Prunet (eds.), The Special Status of Coronals: Internal and External Evidence, 1-28. Sand Diego: Academic Press.

Prince, A. (1997a). Stringency and Anti-Paninian Hierarchies. Available at http:// ling.rutgers.edu/ people/faculty/prince.html.

Prince, A. (1997b). Harmonic Completeness, AP order, Chain Shifts. Available at http:// ling.rutgers.edu/ people/ faculty/prince.html.

Prince, A. (1999). Paninian Relations. Available at http://ling.rutgers.edu/people/ faculty/prince.html.

Prince, A., \& P. Smolensky. (1993). Optimality Theory: Constraint interaction in generative grammar. Cambridge, MA: MIT Press.

Roca, I., \& W. Johnson. (1999). A Course in Phonology. Oxford: Blackwell. 
Rogers, H. (2000). The Sounds of Language: An Introduction to Phonetics. New York: Longman.

Sassoon, R. (1995). The Acquisition of a Second Writing System. Oxford: Intellect.

Selinker, L. (1972). Interlanguage. International Review of Applied Linguistics, 10, 209-231. http://dx.doi.org/10.1515/iral.1972.10.1-4.209

Shattuck-Hufnagel, S., \& D. H. Klatt. (1979). The limited use of distinctive features and markedness in speech production: Evidence from speech error data. Journal of Verbal Learning and Verbal Behavior, 18, 41-55. http://dx.doi.org/10.1016/S0022-5371(79)90554-1

Su, R. S. C. (1996). A study on the English-speaking problem of Chinese Students in Taiwan. Bulletin of National Pingtung Polytechnic Institute, 5(1), 75-86.

Tarone, E. (1980). Some influences on the syllable structure of interlanguage phonology. International Review of Applied linguistics, 18, 139-152.

Tesar, B., \& P. Smolensky. (2000). Learnability in Optimality Theory. Massachusetts: The MIT Press.

Thompson, I. (1991). Foreign accents revisited: the English pronunciation of Russian immigrants. Language Learning, 41, 177-204. http://dx.doi.org/10.1111/j.1467-1770.1991.tb00683.x

Wan, I. P. (2002). Asymmetry in Mandarin consonant articulations: evidence from slips of the tongue. Concentric: Studies in English Literature and Linguistics, 28(2), 1-25.

Wang, C. (1995). The Acquisition of English Word-final Obstruents by Chinese Speakers. Ph.D. dissertation, State University of New York at Stony Brook, New York.

Wardhaugh, R. (1970). The contrastive analysis hypothesis. TESOL Quarterly, 4, 123-130. http://dx.doi.org/10.2307/3586182

Wei, H. L. (1997). A Study of the Production and Perception of the English Obstruents by Chinese EFL Students. Master Thesis. National Taiwan Normal University.

White, L. (1987). Markedness and second language acquisition: the question of transfer. Studies in Second Language Acquisition, 9, 261-285. http://dx.doi.org/10.1017/S0272263100006689

Wilson, C. (2001). Consonant cluster neutralization and targeted constraints. Phonology, 18, 147-197.

Wode, H. (1976). Developmental sequences in naturalistic second language acquisition. Working Papers in Bilingualism, 11, 1-31.

Yavas, M. S. (2006). Applied English phonology. Malden, MA: Blackwell.

Zoll, C. (1996). Parsing Below the Segment in a Constraint Based Framework. Ph.D. dissertation, University of California, Berkeley.

Zoll, C. (1997). Conflicting directionality. Phonology, 14, 263-286. http://dx.doi.org/10.1017/S0952675797003369

Zoll, C. (2004). Positional Asymmetries and Licensing. In J. McCarthy (ed.), Optimality Theory in Phonology: A reader, 365-378. Oxford: Blackwell. (Available on Rutgers Optimality Archive, ROA) http://dx.doi.org/10.1002/9780470756171.ch18

\section{Appendix I English Production Experiment}

\begin{tabular}{|c|c|c|}
\hline No. & $\begin{array}{c}\text { Target } \\
\text { Words }\end{array}$ & Target Sentences \\
\hline 1 & pim & Jessica's grandmother has a red dog which is called Pim. \\
\hline 2 & pin & The English verb 'pin' refers to fasten things together with a pin. \\
\hline 3 & ping & Jessica went straight down Brighton street after hearing a quite loud ping. \\
\hline 4 & sim & When you speak English, don't say the word sim. It's wrong. \\
\hline 5 & sin & In this city, these people have no sense of sin. \\
\hline 6 & sing & Sung is the perfect participle of the bare verb sing. \\
\hline 7 & kim & The gifts, cats, hats and bats, were for Kim. \\
\hline 8 & kin & Are they the same age? Are they kin? \\
\hline 9 & king & The man in black is laughing at the young king. \\
\hline 10 & same & Her nickname is Pitty Pam, rather than Pitty Same. \\
\hline
\end{tabular}




\begin{tabular}{|c|c|c|}
\hline 11 & sane & She is so angry at Kim that she is not acting sane. \\
\hline 12 & [sey] & When speaking English, don't say the non-English word [sey]. It's wrong. \\
\hline 13 & came & In English, the past tense of the bare verb 'come' is came. \\
\hline 14 & cane & She picked tea, picked oranges, cleared fields, and sold sugar cane. \\
\hline 15 & {$\left[\mathrm{k}^{\mathrm{h}} \mathbf{e n}\right]$} & When speaking English, please don't say the non-English word [ $\left.\mathbf{k}^{\mathrm{h}} \mathbf{e n}\right]$. \\
\hline 16 & bam & We bought a kind of fruit called bam. \\
\hline 17 & ban & Tell me how to spell the word 'ban'. \\
\hline 18 & bang & May and I really dislike the English song called 'Bang'. \\
\hline 19 & pam & When they play cards, Kim always beats Pam. \\
\hline 20 & pan & Kim always fries eggs and bacon in a pan. \\
\hline 21 & pang & After Peter and Mary's dog died, they felt a sudden pang. \\
\hline 22 & some & As for [som], do you mean the same sound as some? \\
\hline 23 & sun & In the winter, people miss the heat and light of the sun. \\
\hline 24 & sung & It is wrong to say 'I have sang' in English; the correct way is 'I have sung'. \\
\hline 25 & gum & Tina bought ten pairs of dark tan shoes and later bought gum. \\
\hline 26 & gun & The drunken man with a long hair in blue has a black gun. \\
\hline 27 & gung & When speaking German, don't say the wrong word '[g⿵ngl'. \\
\hline 28 & [ph $\mathrm{hm}$ & 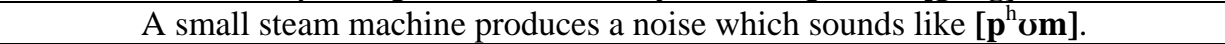 \\
\hline 29 & [p $\left.\mathbf{p}^{\mathrm{h}} \mathbf{\sigma n}\right]$ & 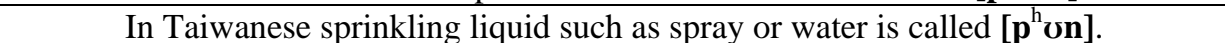 \\
\hline 30 & {$\left[\mathbf{p}^{\mathrm{h}} \mathbf{o n ]}\right.$} & A big steam machine produces a noise which sounds like [p $\left.\mathbf{p}^{\mathrm{h}} \boldsymbol{v}\right]$ ]. \\
\hline 31 & [som] & Both my uncle's surname and my aunt's given name are [som]. \\
\hline 32 & [son] & In Taiwanese bamboo shoots, a kind of edible vegetable, are called [son]. \\
\hline 33 & [son] & 'Magician', a leading role in the video game, produces a voice which sounds like [son]]. \\
\hline 34 & {$\left[\mathbf{k}^{\mathrm{h}} \boldsymbol{\sigma} \mathbf{m}\right]$} & My grandfather's nickname, rather than my father's, is [ $\left.\mathbf{k}^{\mathrm{h}} \mathbf{v m}\right]$ \\
\hline 35 & {$\left[k^{h}\right.$ on] } & In classical or formal Mandarin an elder brother is called [ $\left.\mathbf{k}^{\mathrm{h}} \mathbf{w n}\right]$. \\
\hline 36 & {$\left[\mathbf{k}^{\mathrm{h}} \mathbf{w} \boldsymbol{\eta}\right]$} & In Mandarin Chinese, "to fall asleep" is called [ $\left.\mathbf{k}^{\mathrm{h}} \mathbf{v \eta}\right]$. \\
\hline 37 & [som] & Do you know any words pronounced [som]? \\
\hline 38 & sone & That sound made by Tim had a loudness of one sone. \\
\hline 39 & song & In English, please say 'I have sung a song', but not 'I have singed a song'. \\
\hline 40 & comb & Mr. Wang's and his wife's hair needs a good comb. \\
\hline 41 & cone & Would you like to eat ice cream from cone? \\
\hline 42 & Kong & My uncle's given name and my aunt's surname are Kong. \\
\hline 43 & home & Go by there and take Joleen and Tank home. \\
\hline 44 & hone & Go to a hardware store and buy me a hone. \\
\hline 45 & Hong & In Mandarin Chinese, 'noise, uproar, or quarrel' is called Hong. \\
\hline 46 & bomb & That play and its related products turned out to be a total bomb. \\
\hline 47 & [ban] & In German, sounds correspond to spelling and thus 'ban' is pronounced [ban]. \\
\hline 48 & bong & Tina's neighbors always make a loud noise sounding like a bong. \\
\hline 49 & [pham] & There is a kind of bread with different nuts on a small island, called [ $\left.\mathbf{p}^{\mathrm{h}} \mathbf{a m}\right]$. \\
\hline 50 & [p $\mathbf{p}^{\mathrm{h}} \mathbf{a n ]}$ & In German, sounds correspond to spelling and thus 'pan' is pronounced [phan]. \\
\hline 51 & pong & informal word which means an unpleasant smell is pon \\
\hline
\end{tabular}

\section{(cc) $E Y$}

This work is licensed under a Creative Commons Attribution 3.0 License. 